\title{
PICARD payload thermal control system and general impact of the space environment on astronomical observations
}

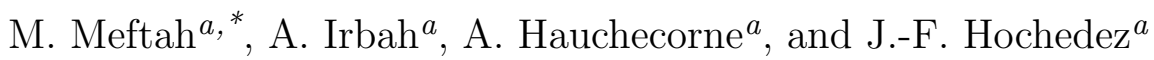 \\ ${ }^{a}$ LATMOS - Laboratoire Atmosphères, Milieux, Observations Spatiales, CNRS - Université \\ Paris VI \& Université de Versailles Saint-Quentin-en-Yvelines - IPSL, F-78280, Guyancourt, Fr
}

\begin{abstract}
PICARD is a spacecraft dedicated to the simultaneous measurement of the absolute total and spectral solar irradiance, the diameter, the solar shape, and to probing the Sun's interior by the helioseismology method. The mission has two scientific objectives, which are the study of the origin of the solar variability, and the study of the relations between the Sun and the Earth's climate. The spacecraft was successfully launched, on June 15, 2010 on a DNEPR-1 launcher. PICARD spacecraft uses the MYRIADE family platform, developed by CNES to use as much as possible common equipment units. This platform was designed for a total mass of about $130 \mathrm{~kg}$ at launch. This paper focuses on the design and testing of the TCS (Thermal Control System) and in-orbit performance of the payload, which mainly consists in two absolute radiometers measuring the total solar irradiance, a photometer measuring the spectral solar irradiance, a bolometer, and an imaging telescope to determine the solar diameter and asphericity. Thermal control of the payload is fundamental. The telescope of the PICARD mission is the most critical instrument. To provide a stable measurement of the solar diameter over three years duration of mission, telescope mechanical stability has to be excellent intrinsically, and thermally controlled. Current and future space telescope missions require ever-more dimensionally stable structures. The main scientific performance related difficulty was to ensure the thermal stability of the instruments. Space is a harsh environment for optics with many physical interactions leading to potentially severe degradation of optical performance. Thermal control surfaces, and payload optics are exposed to space environmental effects including contamination, atomic oxygen, ultraviolet radiation, and vacuum temperature cycling. Environmental effects on the performance of the payload will be discussed. Telescopes are placed on spacecraft to avoid the effects of the Earth atmosphere on astronomical observations (turbulence, extinction, ...). Atmospheric effects, however, may subsist when spacecraft are launched into low orbits, with mean altitudes of the order of $735 \mathrm{~km}$.
\end{abstract}

Keywords: PICARD, SODISM, Telescope, Sun, Thermal Control System, Contamination, Space environment

\section{INTRODUCTION}

PICARD, a French solar physics spacecraft (Figure 1) was launched from the Dombarovsky air base near Yasny (Russia). The mission was named in honour of the Seventeenth century French astronomer Jean Picard (16201682), who made the first long-term measurements of the solar diameter. Picard is an investigation dedicated to the simultaneous measurement of the absolute total and part of spectral solar irradiance, the measurement of solar diameter by metrological instrumentation, and the study of the Sun's interior through helioseismology. The scientific objectives of the mission are described in detail by Thuillier et al. ${ }^{1}$ in 2006. PICARD with French multi-institutional and international cooperation operates during the solar cycle 24. A dawn/dusk orbit with LTAN (Local Time of Ascending Node) at 6:00/18:00 hours is being used with an altitude of $735 \mathrm{~km}$ (period of 99.4 minutes) and an inclination of 98.29 degrees. The selection of a SSO orbit (Sun Synchronous Orbit) permits the period of eclipses to be limited to around 90 days (during winter solstice), and the duration of eclipses to a maximum of 20 minutes.

The Picard spacecraft (total mass near $130 \mathrm{~kg}$ ) consists of a box structure $(0.9 \mathrm{~m} \times 0.8 \mathrm{~m} \times 1.1 \mathrm{~m})$ with a single solar panel. The platform structure is made of a massive aluminium base plate interfacing with the launcher, four lateral honeycomb panels, and a payload base plate (Figure 2). The payload is composed of three instruments

\footnotetext{
* Corresponding author

E-mail address: Mustapha.Meftah@latmos.ipsl.fr
} 
and an electronic box named PGCU (PICARD Gestion Charge Utile or Payload Management Unit) including the electronics associated with SODISM (SOlar Diameter Imager and Surface Mapper) and the processor in charge of the payload data handling and control. The scientific measurements are achieved by:

- PREMOS ${ }^{2}$ (PREcision MOnitoring Sensor) is made of four units: a set of three Sun-photometers and a PMO6 radiometer as used on SoHO to measure the absolute Total Solar Irradiance. The Sun-photometers are used to study the ozone photochemistry, to perform helioseismologic observations, and to relate radiance/irradiance observations with the corresponding images recorded by the SODISM imaging telescope as described below. PREMOS measures at 215, 268, 535, 607, and $782 \mathrm{~nm}$. The PREMOS instrument is under the responsibility of the Physikalisch-Meteorologisches Observatorium Davos - World Radiation Center (PMOD - WRC, Switzerland). - SOVAP ${ }^{3}$ (SOlar VAriability PICARD) instrument provided by the Royal Meteorological Institute of Belgium (RMIB) measures the absolute Total Solar Irradiance. This instrument is a radiometer of DIARAD type used in previous space missions, SOHO, and SOLCON on the Space Shuttle (1992, 1993, 1994, 1998, and 2003). There is also a bolometer provided by the Royal Observatory of Belgium (ROB).

- SODISM ${ }^{4}$ is an imaging telescope measuring the solar diameter and limb shape, and performs helioseismologic observations to probe the solar interior. The solar diameter is measured at three wavelengths $(535.7,607.1$ and $782.2 \mathrm{~nm})$ in the photospheric continuum. Images in the Ca II line $(393.37 \mathrm{~nm})$ are used to detect active regions near the solar limb that may alter the diameter measurements. These images are also used to measure the solar differential rotation as well as for Space Weather, together with images in the $215.0 \mathrm{~nm}$ wavelength. This instrument is provided by CNRS (Centre National de la Recherche Scientifique).

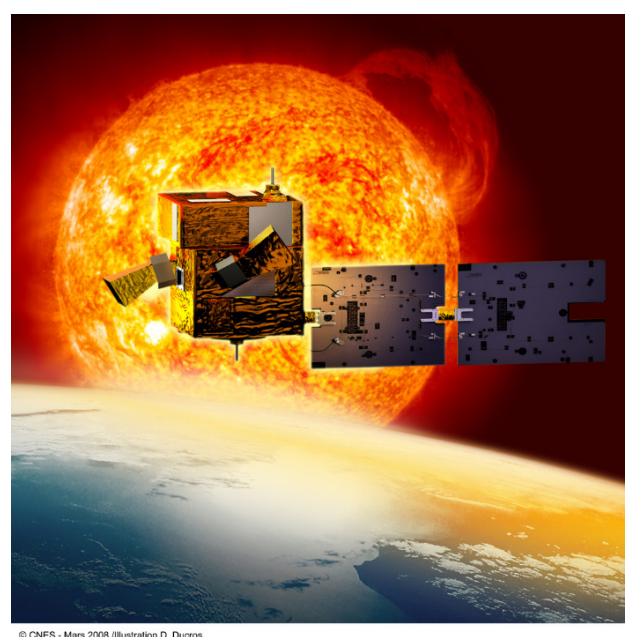

Figure 1. Artist's view of the spacecraft.

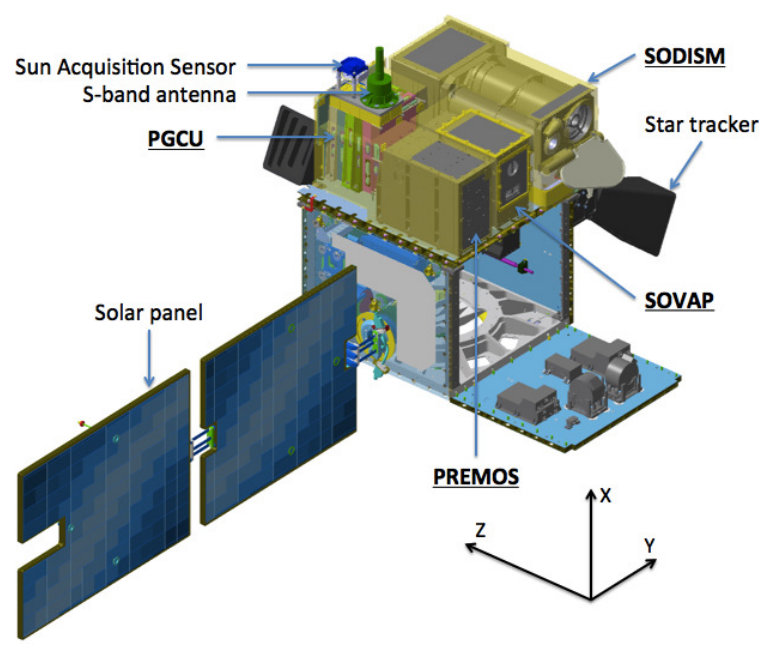

Figure 2. Spacecraft and instruments allocation.

\section{- The purpose of PICARD payload thermal control}

Throughout the mission, thermal control ensures that each instrument or equipment unit is maintained at temperatures consistent with nominal operation. Most of instruments only operate correctly if maintained at the right temperature and if temperature changes are within acceptable limits. In our terrestrial environment or in laboratories, temperatures are often regulated. Spacecraft environments in orbit are completely different (vacuum, microgravity, radiation, ...). Thermal control surfaces and payload optics are exposed to space environmental effects including contamination, atomic oxygen, ultraviolet radiation and vacuum temperature cycling. This means that thermal conditions are very particular and likely to cause important changes in temperature. Correct temperature can only be achieved by specific thermal control technology. Thermal control of the payload is fundamental. To provide a stable measurement of the solar diameter to a few milli-arcseconds over three years duration of mission, the SODISM telescope mechanical stability has to be intrinsically excellent and thermally controlled. It is necessary to ensure low temperature gradients (spatial $\delta T / \delta x$ ), and low temperature variations (temporal $\delta T / \delta t$ ) for a metrological instrument. 


\section{- Contamination and environmental effects on the performance of the payload}

Materials having low values of solar absorptance $\alpha_{s}$ are often used for reflective surfaces designed to minimise heat absorption. Thermal balance can be maintained over the payload lifetime only if the reflective surfaces maintain their thermal properties. The presence of contamination on thermal control surfaces alters absorptance/emittance ratios and changes thermal balance leading to increased payload temperatures. Contamination in optical instruments decreases signal throughput, thus further decreasing performance. The PICARD payload is sensitive to contamination. It was necessary to quantify the critical level of contamination and to enforce contamination control to ensure compliance with requirements. This work is rather complex and not trivial. During fabrication, assembly, integration, test, launch and operation in order to maintain those levels on orbit (opening the door of the instrument one month after the outgassing phase during the commissioning phase), procedures and processes were necessary. Selected payload materials (near optical elements) comply with the following conditions: TML $<0.1 \%$ (Total Mass Loss) and CVCM $<0.01 \%$ (Collected Volatile Condensable Material), according to ESA-PSS-51 (guidelines for spacecraft cleanliness control from European Space Agency), but are not always sufficient for very sensitive surfaces. Effective contamination control is essential for the success of PICARD mission, because the presence of contamination degrades the performance of payload hardware. The payload thermal coatings suffer outgassing and mass loss due to their direct exposure to the thermal environment and high vacuum in space. They also suffer from the ultraviolet radiation and vacuum temperature cycling. Flight performance of the payload thermal control is affected by the contamination. Effects of space environments on the performance of the payload appear and are greater than expected.

In the next section, we describe the PICARD payload TCS (Thermal Control System). In subsequent sections, we present PICARD payload thermal test, in-orbit thermal performance, PICARD/SODISM observational results, and effects of space environments on PICARD/SODISM measurements.

\section{THE PICARD PAYLOAD TCS DESIGN}

Table 1 summarises the main characteristics of the PICARD payload. PGCU is an onboard electronics unit which includes all functions necessary to operate the three instruments (formatting of telemetry, reception of commands, image compression, thermal control and power supply for SODISM, and safety management). PREMOS has its own thermal control. The power consumption of the payload (in orbit, see Table 1) is lower than expected (prediction before the launch).

Table 1. PICARD payload main characteristics.

\begin{tabular}{|c|c|c|c|c|c|c|c|}
\hline Instrument & Mass (kg) & $\mathrm{C}(\mathrm{J} / \mathrm{K})$ & GL $(\mathrm{W} / \mathrm{K})$ & Volume $^{\mathrm{a}}$ & $\mathrm{P}(\mathrm{W})^{\mathrm{b}}$ & $\mathrm{P}(\mathrm{W})^{\mathrm{c}}$ & Dissipation $(\mathrm{W})^{\mathrm{c}}$ \\
\hline PREMOS & 9.74 & 9,356 & 0.105 & $267 \times 176 \times 354$ & 14.70 & 17.13 & $13.68+3.45^{\dagger}$ \\
\hline SOVAP & 9.10 & 9,075 & 0.120 & $268 \times 180 \times 347$ & 9.87 & 10.50 & 10.50 \\
\hline SODISM & 26.40 & 19,784 & 0.110 & 300x308x670 & - & - & $4+7.81^{\dagger}$ \\
\hline PGCU & 10.80 & 9,665 & 0.110 & $306 \times 304 \times 223$ & 30.57 & 32.11 & 20.3 \\
\hline Harness & 2.50 & 951 & 0.120 & $306 \times 670 \times 670$ & - & - & - \\
\hline Total & 58.56 & 48831 & - & $306 \times 670 \times 670$ & 55.14 & 59.74 & 59.74 \\
\hline
\end{tabular}

${ }^{\text {a }}$ Dimensions in mm, ${ }^{\mathrm{b}}$ In orbit, ${ }^{\mathrm{c}}$ Prediction (before the launch), ${ }^{\dagger}$ Active thermal control of instrument

\subsection{Temperature requirements}

The purpose of the thermal control design is to maintain all the instruments or equipment units of the spacecraft system within their temperature limits for all mission phases from launch to end of life. The thermal control (passive and active) ensures that the payload, and its subsystems work within the acceptance temperature range (see Table 2) in every phase of the mission.

The qualification margin is equal to $\left|T_{Q}-T_{A}\right|$. The uncertainties (coming from complex view factors, surface properties, radiation environment, joints, interface conduction, and ground tests) recognise that many assumptions are used in the development of thermal mathematical models (uncertainties of $5^{\circ} \mathrm{C}$ after thermal balance test correlation). 
Table 2. PICARD payload temperature requirements.

\begin{tabular}{|l|l|cc|}
\hline Payload & Requirements & $T_{Q}$ & $T_{A}$ \\
\hline PREMOS & Minimum Non-Operating Temperature & $-40^{\circ} \mathrm{C}$ & - \\
& Minimum Operating Temperature & $-20^{\circ} \mathrm{C}$ & - \\
& Maximum Operating Temperature & $60^{\circ} \mathrm{C}$ & - \\
& Maximum Non-Operating Temperature & $65^{\circ} \mathrm{C}$ & - \\
\hline SOVAP & Minimum Non-Operating Temperature & $-40^{\circ} \mathrm{C}$ & $-30^{\circ} \mathrm{C}$ \\
& Minimum Operating Temperature & $-25^{\circ} \mathrm{C}$ & $-20^{\circ} \mathrm{C}$ \\
& Maximum Operating Temperature & $45^{\circ} \mathrm{C}$ & $40^{\circ} \mathrm{C}$ \\
& Maximum Non-Operating Temperature & $60^{\circ} \mathrm{C}$ & $50^{\circ} \mathrm{C}$ \\
\hline SODISM & Minimum Non-Operating Temperature & $-35^{\circ} \mathrm{C}$ & $-30^{\circ} \mathrm{C}$ \\
& Minimum Operating Temperature & $0^{\circ} \mathrm{C}$ & $5^{\circ} \mathrm{C}$ \\
& Maximum Operating Temperature & $40^{\circ} \mathrm{C}$ & $35^{\circ} \mathrm{C}$ \\
& Maximum Non-Operating Temperature & $50^{\circ} \mathrm{C}$ & $45^{\circ} \mathrm{C}$ \\
\hline PGCU & Minimum Non-Operating Temperature & $-40^{\circ} \mathrm{C}$ & $-35^{\circ} \mathrm{C}$ \\
& Minimum Operating Temperature & $-30^{\circ} \mathrm{C}$ & $-20^{\circ} \mathrm{C}$ \\
& Maximum Operating Temperature & $50^{\circ} \mathrm{C}$ & $40^{\circ} \mathrm{C}$ \\
& Maximum Non-Operating Temperature & $60^{\circ} \mathrm{C}$ & $55^{\circ} \mathrm{C}$ \\
\hline
\end{tabular}

${ }^{*}$ Proto-flight model, $T_{Q}$ : Qualification levels, $T_{A}$ : Flight acceptance levels

\subsection{The PICARD payload TCS}

On the payload, there is passive thermal control: thermal insulation (MultiLayer Insulation or MLI), radiators, surface finishes (coatings, paints, treatments, Second Surface Mirrors, tape, Optical Solar Reflector), and thermal washers to reduce the thermal coupling at platform interfaces. There is also active thermal control: resistance heaters with mechanical thermostat, and electronic controllers. The PREMOS instrument is thermally regulated (locally) in operating mode. SOVAP and PGCU are not thermally regulated. SODISM is thermally regulated (overall) in operating mode with the exception of elements in the front face (optical front window, door). The PICARD payload consists of several radiators: devices with a large surface area used to radiate heat (heat rejection). For our application, it is desirable to have a high value of emissivity $\varepsilon$ (3 to $100 \mu m$ wavelength band) and a low value of $\alpha$ (0.2 to $3 \mu \mathrm{m}$ wavelength band) in order to maximise the heat rejection in space and to minimise the solar radiation. Thermal coatings are very efficient. Unfortunately, they will degrade over time. The position of the radiators is shown in Figure 3. The spacecraft, during integration, is shown in Figure 4. Thermal control coatings surfaces, such as white paints, silvered or aluminized Second Surface Mirrors (SSM), Back Surface Mirrors (BSM), that have special radiation properties are used (Table 3).

Table 3. PICARD payload radiators and optics characteristics.

\begin{tabular}{|l|l|l|c|c|}
\hline Payload & Denomination & Coating surface & $\alpha_{B O L} / \alpha_{E O L}$ & $\varepsilon_{B O L} / \varepsilon_{E O L}$ \\
\hline PREMOS & -Z radiator (Sunshield) & BSM & $0.09 / 0.15$ & $0.81 / 0.81$ \\
& + X radiator & Aluminized SSM & $0.15 / ?^{\star}$ & $0.91 / 0.91$ \\
\hline \multirow{2}{*}{ SOVAP } & -Z radiator & Silvered SSM & $0.14 / 0.18$ & $0.75 / 0.75$ \\
& + X radiator & SG121FD white paint & $0.3 / ?^{\star}$ & $0.88 / 0.88$ \\
\hline \multirow{2}{*}{ SODISM } & +X radiator 1 & Silvered SSM & $0.14 / 0.18$ & $0.75 / 0.75$ \\
& +X radiator 2 & SG121FD white paint & $0.25 / ?^{\star}$ & $0.88 / 0.88$ \\
& +Y radiator (CCD) & SG121FD white paint & $0.25 / ?^{\star}$ & $0.88 / 0.88$ \\
& Door & Silvered SSM & $0.14 / 0.18$ & $0.75 / 0.75$ \\
& Front window (or Entrance window) & Optical coating & $0.15 / ?^{\star}$ & $0.81 / 0.81$ \\
\hline PGCU & +Z radiator & SG121FD & $0.25 / ?^{\star}$ & $0.88 / 0.88$ \\
\hline
\end{tabular}

BOL: Begin Of Life, EOL: End Of Life (design hypothesis, *Unknown ageing) 


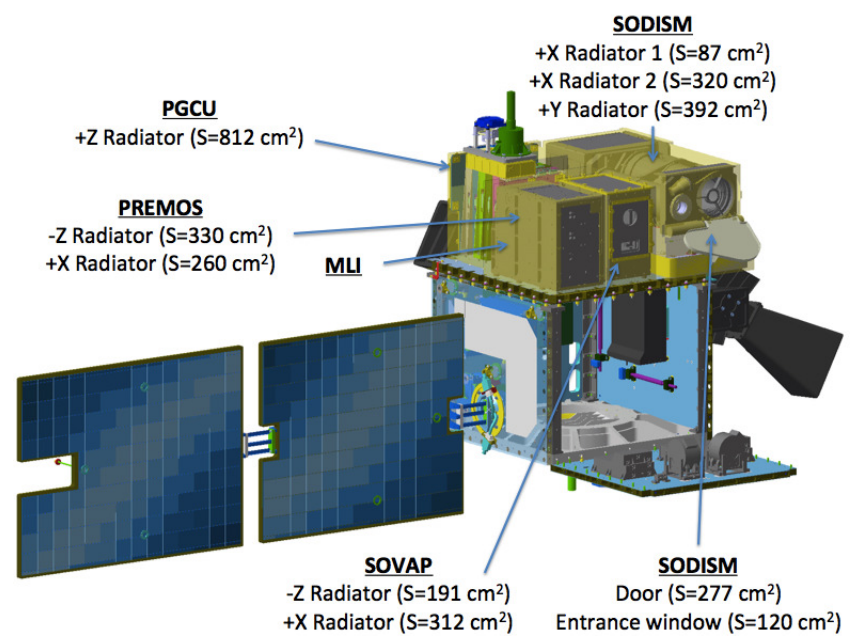

Figure 3. Radiators of the spacecraft.

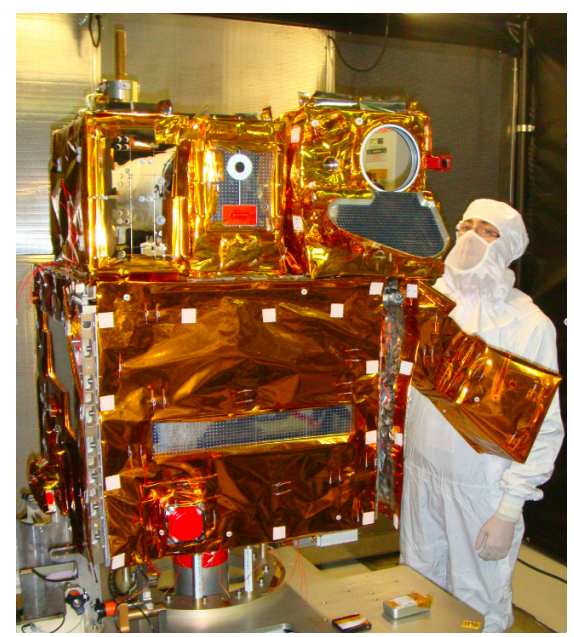

Figure 4. Spacecraft during integration.

\subsection{SODISM thermal design}

SODISM is the most critical instrument. The resulting temperature range in orbit is foreseen to be about $-35^{\circ} \mathrm{C}$ to $50^{\circ} \mathrm{C}$ in non-operating mode (Table 2), avoiding any degradation of structure, electronics and optical parts. SODISM requires a very high level of thermo-mechanical stability to obtain the desired accuracy on solar diameter measurements (in operating mode). A complex thermal control is implemented on the telescope and consists of i) efficient thermal protection (Multi Layer Insulation or MLI) of the overall telescope, ii) protection from solar illumination, iii) the implementation of a complex heating system monitored by thermal sensors. The thermal control includes the necessary hardware to control the temperature of all components of the telescope, including the structure, the mirrors, the mechanisms and also the temperature regulation algorithm. The SODISM thermal control is based on a Proportional Integral (PI) regulation. The instrument stability strongly depends upon precise regulation of all defined parameters. The temperature control provides several independent temperature controlled areas located over the structure. Each area consists of a set of heaters, mounted in the same electrical circuit, over which the heating power is adjusted based on the temperature measured through a temperature sensor located in the vicinity of the heaters. Most important temperature controlled areas are redundant. The temperature set point of each area is reprogrammable and was adjusted during the commissioning phase. 20 heating lines are used to thermally stabilise the instrument at $\sim 20^{\circ} \mathrm{C}$ (operating mode). Temperature sensors are used for the temperature regulation process, as well as for temperature housekeeping over the telescope (45 sensors). The most sensitive elements are:

- The mirrors: they must be regulated (primary mirror at $25^{\circ} \mathrm{C} \pm 1^{\circ} \mathrm{C}$ and secondary mirror at $30^{\circ} \mathrm{C} \pm 1^{\circ} \mathrm{C}$ ).

- The interference filters: they must be regulated at $20^{\circ} \mathrm{C} \pm 5^{\circ} \mathrm{C}$ (central wavelength stabilisation).

- The CCD (Charge Coupled Device): it has to be thermally regulated at $-10^{\circ} \mathrm{C} \pm 0.2^{\circ} \mathrm{C}$ to have no area deformations and low noise in images. The dark signal is an unwanted component of the recorded datum at each CCD picture element (pixel). The Telescope needs to be kept at room temperature, but the CCDs need to be kept at extremely cold temperatures $\left(\sim-40^{\circ} \mathrm{C}\right)$. This is extremely difficult to achieve, given that we are on a low Earth orbit (LEO). In fact, the incident flux (Outgoing Longwave Radiation and Reflected Solar Radiation) at the CCD radiator are not negligible. In addition, the spacecraft has a small mass (thermal inertia) and the electrical power allocated to the thermal control of the instrument is low.

The front window is not temperature-regulated (passive thermal control). This is another problem related to the nature of the optical element (very low thermal conductivity and inability to integrate a thermal heater). However, it is necessary to ensure its temperature (between 0 and $40^{\circ} \mathrm{C}$ during operating mode). The front window is thermally insulated from the mechanical structure to avoid optical lens effects due to its deformations by thermal constraints. 


\subsection{The MLI (Multi Layer Insulation)}

Each instrument or equipment unit of the payload has its own MLI. There is also MLI for the entire payload (to avoid solar trapping). Each instrument external blanket or MLI consists of 15 layers defined as follows: one external layer (space side, $25 \mu \mathrm{m}$ Kapton), 13 intermediate layers (6 $\mu \mathrm{m}$ Mylar and Dacron) and 1 internal layer (internal side, $25 \mu \mathrm{m}$ Kapton). For the MLI, it is desirable to have a low value of $\varepsilon_{\text {equivalent }}(0.014)$ and a low value of $\lambda_{\text {equivalent }}\left(0.025 \mathrm{~W} \cdot \mathrm{m}^{-2} \cdot \mathrm{K}^{-1}\right)$. The main characteristics of the payload external layer are: $\varepsilon=0.77$, $\alpha_{B O L}=0.32$, and $\alpha_{E O L}=0.49$.

\subsection{Thermal Environments}

PICARD is a metrology mission. The flux variations (thermal environments) affect the temperature of the payload. When temperatures change (orbital variation, effect of eclipses, long-term variation), instrument performance is impacted. The annual mean global energy balance for the Earth-atmosphere system is very important to understand. Of the $342 \mathrm{~W} / \mathrm{m}^{2}$ incoming solar radiation (Shortwave Radiation), $67 \mathrm{~W} / \mathrm{m}^{2}$ are absorbed during passage through the atmosphere (clouds). A total of $107 \mathrm{~W} / \mathrm{m}^{2}$ (Reflected Short-wave Radiation) is reflected back to space (clouds and Earth's surface) in the 0.2 to $3 \mu \mathrm{m}$ wavelength band. Shortwave radiation is a term used to describe radiant energy with wavelengths near-UltraViolet (UV), in the VISible (VIS), and Near-InfraRed (NIR) spectra. The remaining $168 \mathrm{~W} / \mathrm{m}^{2}$ are absorbed at the Earth's surface.

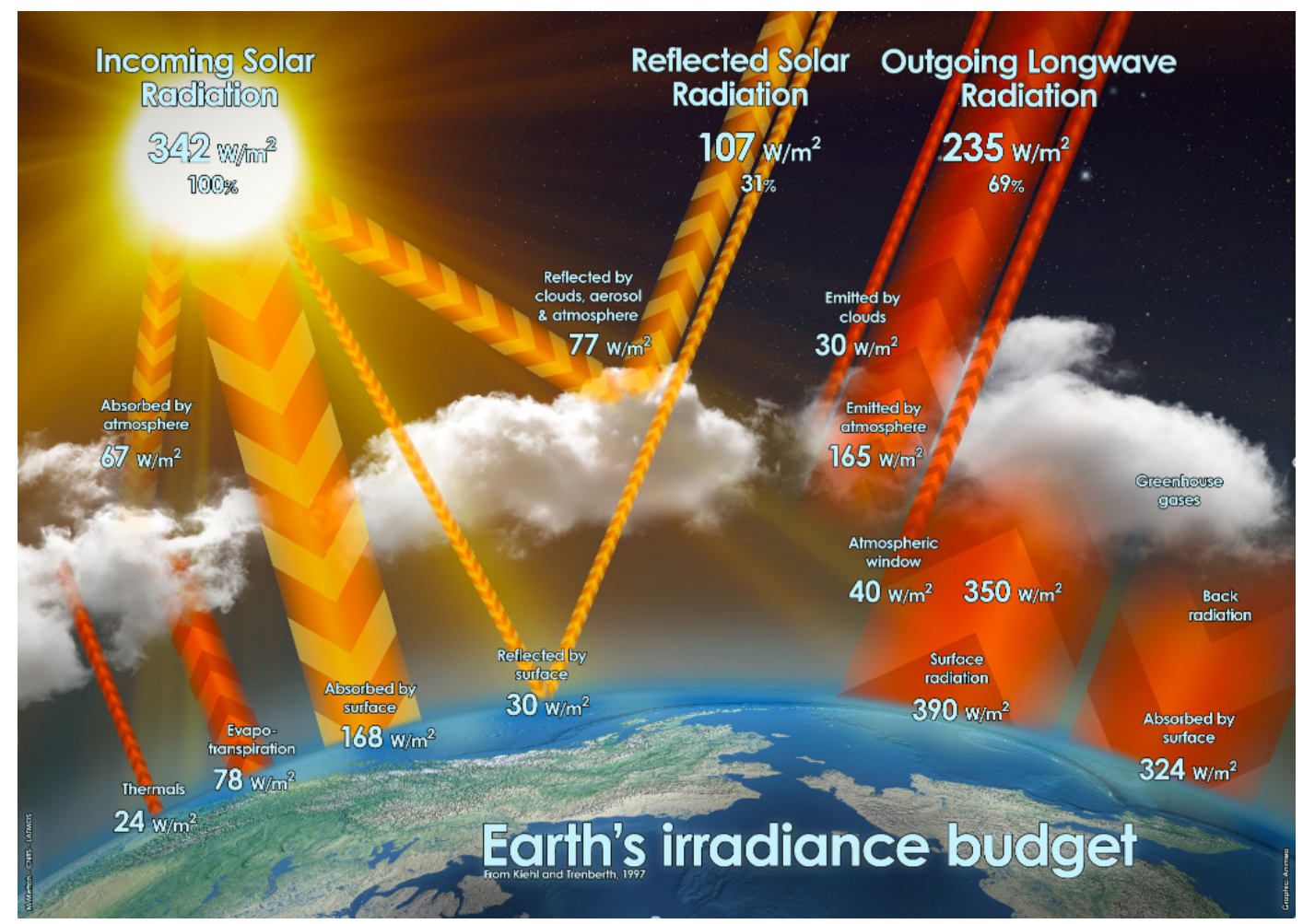

Figure 5. Earth Radiation Budget.

In order to maintain a stable climate, the Earth must be in energetic equilibrium between the radiation it receives from the Sun and the radiation it emits out to space. Outgoing Long-wave Radiation (OLR radiation in the 3 to $100 \mu \mathrm{m}$ wavelength band) is the energy leaving the Earth as infrared radiation at low energy (235 $\mathrm{W} / \mathrm{m}^{2}$ emitted). The OLR is affected by the Earth's skin temperature, skin surface emissivity, atmospheric temperature, water vapour profile, clouds and dust in the atmosphere, which tend to reduce it below clear sky values. Greenhouse gases, such as methane (CH4), nitrous oxide (N2O), water vapour (H2O) and carbon dioxide (CO2), absorb certain wavelengths of OLR adding heat to the atmosphere, which in turn causes the atmosphere to emit more radiation. The effect of clouds on the radiation budgets at the Top Of Atmosphere (TOA) derived 
from the Earth Radiation Budget Experiment (ERBE) [Barkstrom et al. ${ }^{5}$ ] has been widely used to validate climate models and to improve cloud parameterisation schemes. The following Table 4 summarises the range of Direct Solar, Reflected Solar (Albedo), and Planetary Infrared (IR) for the Earth.

Table 4. Thermal Environments for analysis.

\begin{tabular}{llll}
\hline & Perihelion & Aphelion & Mean \\
\hline Direct Solar & $1414 \mathrm{~W} / \mathrm{m}^{2}$ & $1322 \mathrm{~W} / \mathrm{m}^{2}$ & $1366.6 \mathrm{~W} / \mathrm{m}^{2}$ \\
Albedo (global average) & 0.35 & 0.27 & 0.31 \\
Earth Reflected Solar (global average) & $124 \mathrm{~W} / \mathrm{m}^{2}$ & $89 \mathrm{~W} / \mathrm{m}^{2}$ & $107 \mathrm{~W} / \mathrm{m}^{2}$ \\
Planetary Infrared (global average) & $230 \mathrm{~W} / \mathrm{m}^{2}$ & $241 \mathrm{~W} / \mathrm{m}^{2}$ & $235 \mathrm{~W} / \mathrm{m}^{2}$ \\
\hline
\end{tabular}

\subsection{The spacecraft pointing and incident fluxes on the spacecraft}

The spacecraft is three-axis stabilised. The attitude and orbit control system provides a pointing stability better than 36 arc-seconds for the $\mathrm{Z}$ axis of the spacecraft (inertial pointing and $-\mathrm{Z}$ axis Sun oriented). Two parameters affect the orientation of the spacecraft with regard to the Earth. These are the declination of the Sun and the position angle $\mathrm{P}$ of the Sun. This effect has an impact on the temperature of the spacecraft (relationship between the latitude of the Earth and temperature). The declination of the Sun is the angle between the rays of the Sun and the plane of the Earth's equator. At the solstices, the declination reaches its maximum value of $23.43^{\circ}$. At the winter solstice, which occurs near December 21, the North Pole is pointing away from the Sun at an angle of $23.43^{\circ}$. Therefore the apparent declination of the Sun is $-23.43^{\circ}$ with respect to the celestial equator. The Sun rotates on its axis once in about 27 days. The Sun's rotation axis is tilted by about $7.25^{\circ}$ from the axis of the Earth's orbit. That is the heliographic latitude B0 of the central point of the solar disk. The range of $\mathrm{B} 0$ is $\pm 7.23^{\circ}$, correcting for the tilt of the ecliptic with respect to the solar equatorial plan. $\mathrm{P}$ is the position angle between the geocentric North Pole and the solar rotational North Pole measured eastward from geocentric North. The range of $\mathrm{P}$ is $\pm 26.3^{\circ}$. The $\mathrm{X}$ axis of the spacecraft follows the position angle $\mathrm{P}$ of the Sun and remains parallel with this axis. The incident fluxes change during the year (Figure 6).
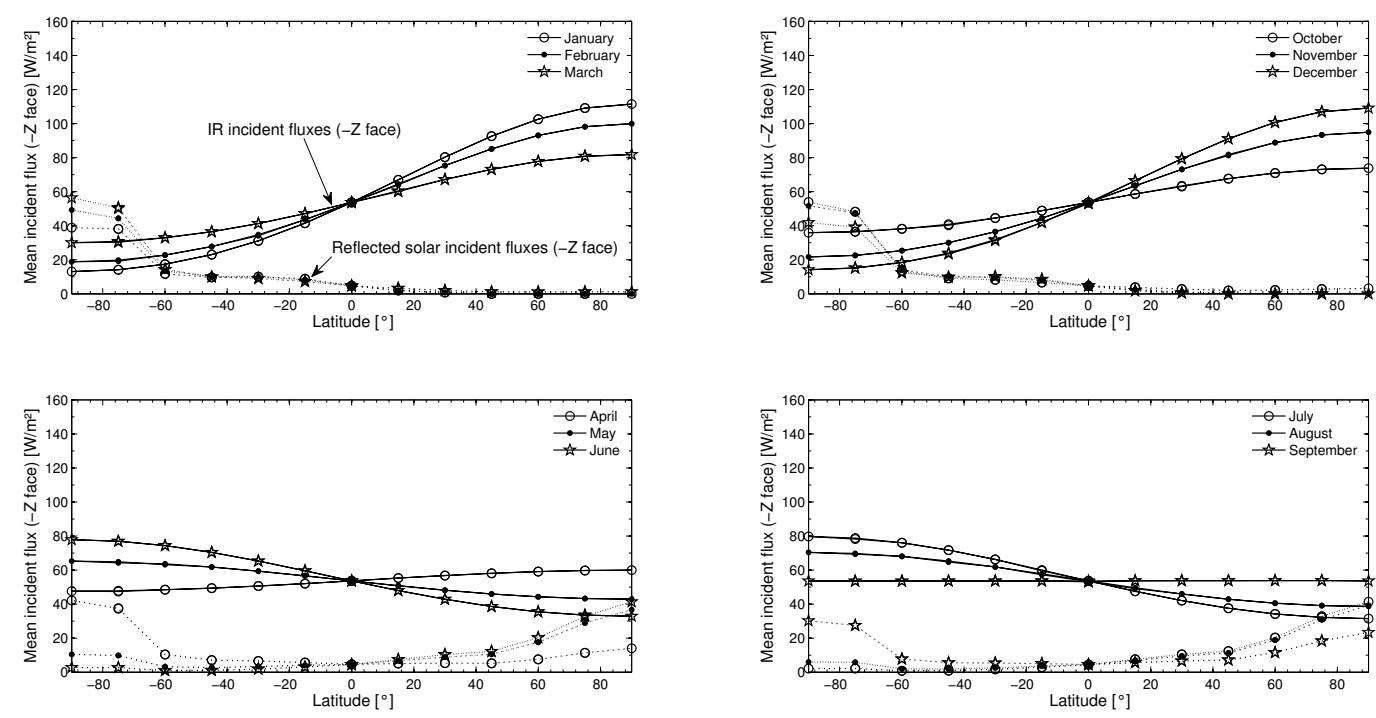

Figure 6. Mean incident IR fluxes and mean reflected solar fluxes (-Z face of the spacecraft). 


\section{THE PICARD PAYLOAD THERMAL TEST}

The thermal balance test has two objectives: obtaining thermal data for thermal mathematical model correlation and verifying the adequacy of the performance of the thermal control subsystem. The thermal balance test was limited (no solar simulator and no optical performance). To provide data for model correlation, individual conditions are simulated in the thermal vacuum chamber and thermal data are taken during temperature transition (for transient correlation) or at equilibrium (for steady-state correlation). The PICARD thermal balance test includes simulations of hot operational phases, cold non-operational phases (safe mode), and transition phases (a simulation of separation with the launcher). Equilibrium temperatures or repeatable heater cycling profiles are typically the thermal data that are recorded during the test. Verification of the thermal control of the payload includes verification of thermal hardware, including heaters, thermostats, flight thermistors, radiators, and interface contact materials. TCS performance with margins is demonstrated from thermal data and hardware verification. The PICARD spacecraft thermal balance test was performed on the flight model. During this test, we also conducted vacuum temperature cycling tests. The vacuum temperature cycle between two extreme temperatures is an environmental stress test used to increase product reliability by precipitating latent defects (caused by workmanship defects, or early failures). Initially, each instrument of the PICARD payload has been qualified individually (four thermal vacuum temperature cycles). The different cases tested are shown in the Table 5. The thermal test was conducted from April 17 to May 1, 2009 (Intespace facility, France). Figure 7 shows PICARD spacecraft mounted to the thermal vacuum chamber as in the flight configuration (without the solar panel). The PICARD payload thermal mathematical model is shown in the Figure 8.

Table 5. Thermal test in the thermal vacuum chamber $\left(-160^{\circ} \mathrm{C}\right.$ and $10^{-6} \mathrm{mbar}$ or $\left.\mathrm{hPa}\right)$.

\begin{tabular}{|l|lll|}
\hline Test & Payload & Thermal control & SODISM door \\
\hline Thermal balance (hot case) & ON & ON & Open \\
Thermal cycling 1 (hot case) & ON & ON & Closed \\
Transition phase near $10^{\circ} \mathrm{C}$ (Figure $9 \rightarrow$ item 1) & OFF & OFF & Closed \\
Thermal balance (cold case) & OFF & OFF & Closed \\
Thermal cycling 1 (cold case) & ON & ON & Closed \\
Thermal cycling 2 (hot case) & ON & ON & Closed \\
Thermal cycling 2 (cold case) & ON & ON & Closed \\
\hline
\end{tabular}

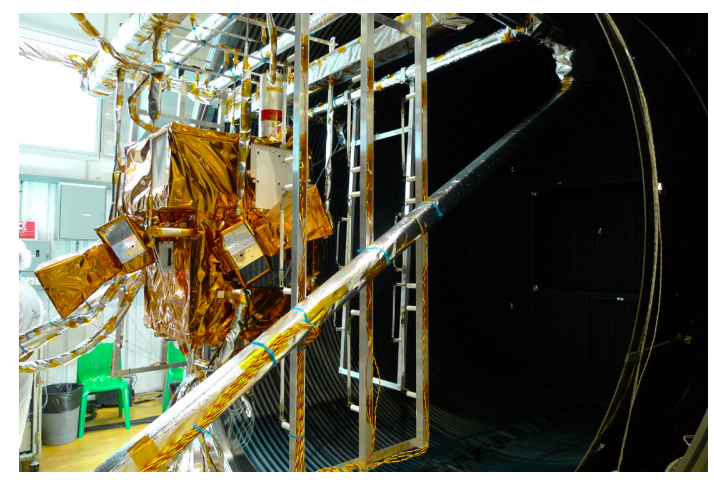

Figure 7. PICARD in the thermal vacuum chamber.

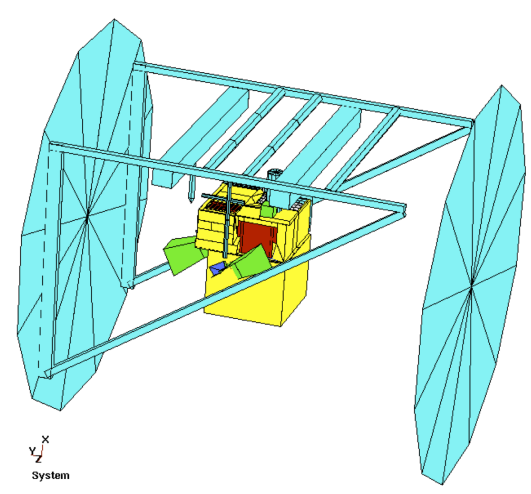

Figure 8. PICARD mathematical model.

Two equilibrium cases for the thermal balance (Hot case - Hc, and Cold case - Cc) were conducted. Test results provided sufficient data to correlate the thermal mathematical model. All sensors match predictions within $5^{\circ} \mathrm{C}$ for both test cases (after correlation). Thermal balance tests temperatures versus thermal mathematical model correlated predictions are provided in Table 6 . The thermal balance test correlation has successfully confirmed the validity of the payload model. 
Table 6. Summary comparison of thermal balance Test (T) vs. Analysis results (A).

\begin{tabular}{|l|ll|ll|}
\hline Instrument & $\mathrm{T}(\mathrm{Hc})$ & $\mathrm{A}(\mathrm{Hc})$ & $\mathrm{T}(\mathrm{Cc})$ & $\mathrm{A}(\mathrm{Cc})$ \\
\hline PREMOS & $26.6^{\circ} \mathrm{C}$ & $25.1^{\circ} \mathrm{C}$ & $-27.7^{\circ} \mathrm{C}$ & $-27.2^{\circ} \mathrm{C}$ \\
SOVAP & $23.6^{\circ} \mathrm{C}$ & $25.6^{\circ} \mathrm{C}$ & $-26.9^{\circ} \mathrm{C}$ & $-27.9^{\circ} \mathrm{C}$ \\
SODISM & $14.6^{\circ} \mathrm{C}$ & $10.8^{\circ} \mathrm{C}$ & $-23.9^{\circ} \mathrm{C}$ & $-25.2^{\circ} \mathrm{C}$ \\
PGCU & $16.7^{\circ} \mathrm{C}$ & $19.1^{\circ} \mathrm{C}$ & $-29.3^{\circ} \mathrm{C}$ & $-25.4^{\circ} \mathrm{C}$ \\
\hline
\end{tabular}

Thermal coatings chosen for the payload are adequate for maintaining instrument temperatures in the flight acceptable range. The evolution of the instruments' Temperature Reference Point (TRP) is given in Figure 9. The PICARD payload requires mechanical thermostats with associated heaters for active thermal control during the non-operating phase (Payload OFF, and safe mode). Before PICARD payload instruments are operational, its stay-alive heaters prepare it for the unpowered phase (thermal switches and heater utilisation are shown in Figure 9 for the SODISM instrument $\rightarrow$ item 2). The spacecraft On Board Computer (OBC) has the ability to control stay-alive heaters for the instruments (Figure 9 for the SODISM instrument $\rightarrow$ item 3 ).
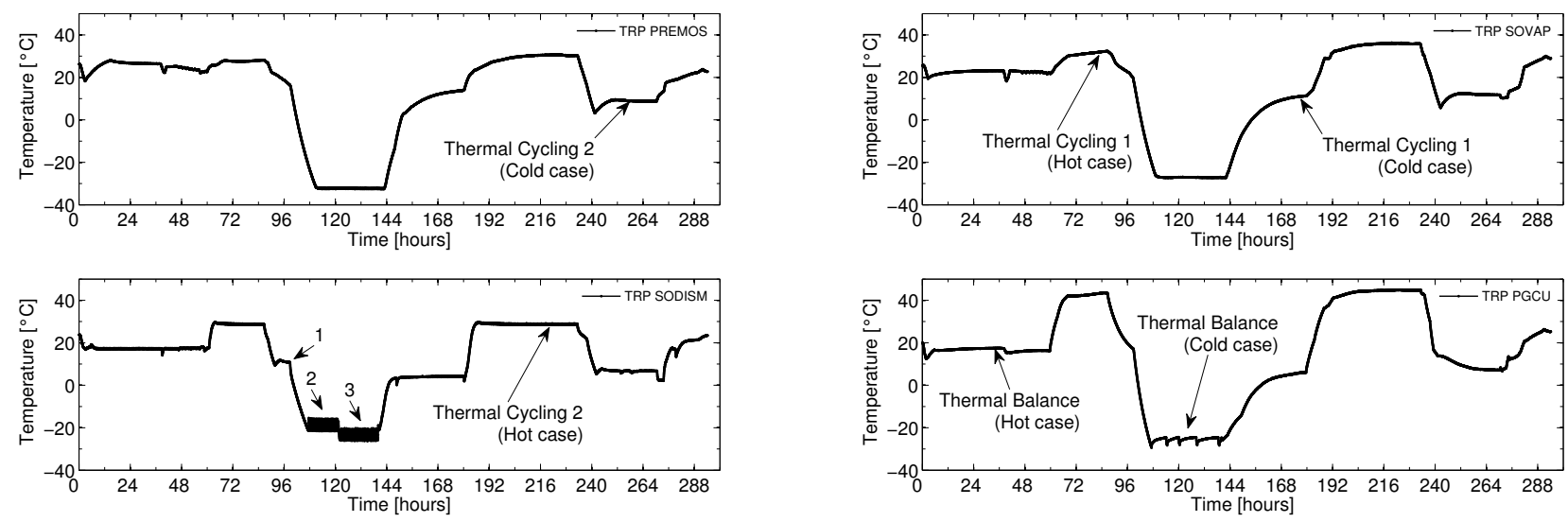

Figure 9. Temperature Reference Point (TRP) changes during the test.

\section{PAYLOAD IN-ORBIT THERMAL PERFORMANCE}

On June 15, 2010, the PICARD spacecraft was launched by a Dnepr-1 launcher. The spacecraft was placed in a $735 \mathrm{~km}$ Sun Synchronous Orbit (06h00) with inclination of 98.28 degrees. A few days later, the PICARD payload was powered on. The cover of the SODISM telescope (door at the entrance of the telescope) was closed. The first weeks in orbit have been dedicated to the outgassing of the payload (SODISM CCD detector was maintained at a temperature above $20^{\circ} \mathrm{C}$ to avoid any contamination). Temperatures of the payload (first month in orbit) are provided in Table 7.

Table 7. In-orbit temperature of the instruments.

\begin{tabular}{|l|ll|}
\hline Instrument & $\mathrm{T}^{\bullet}$ & $\mathrm{T}^{\circ}$ \\
\hline PREMOS & $-28.8^{\circ} \mathrm{C}$ & $26.3^{\circ} \mathrm{C}$ \\
SOVAP & $-27.1^{\circ} \mathrm{C}$ & $23.8^{\circ} \mathrm{C}$ \\
SODISM & $-22.4^{\circ} \mathrm{C}$ & $22.9^{\circ} \mathrm{C}$ \\
PGCU & $-30.0^{\circ} \mathrm{C}$ & $12.9^{\circ} \mathrm{C}$ \\
\hline
\end{tabular}

- In-orbit Payload OFF - June 2010, In-orbit Payload ON - July 2010 
Fluctuations in the PICARD payload temperatures (Figure 10) result from a large number of factors. The thermal effects caused by these factors have a range in duration from hours or days to a long-term of months or years. There are short-term factors (orbital variation, bake-out, switch OFF/ON instrument, spacecraft rotation, stellar calibration). There are several heaters onboard the PICARD payload that are used to maintain a specific thermal environment for the scientific instruments. Despite the establishment of an active thermal control, there is an environmental short-term effect on the instruments. There are also intermediate term factors (Earth eclipses, mean distance to the Sun). Earth eclipses not only resulted in a daily cycle of cooling the payload, but also affected payload temperatures for an extended period following the eclipse season (between November and February). During Earth eclipse seasons, the overall temperature of the spacecraft is reduced. The solar radiation flux varies with the distance from the Sun. Therefore, during the summer months when the Earth is farthest from the Sun, temperatures on the spacecraft generally run slightly lower than during the winter months. And finally, there are long-term factors (decreased equipment unit power dissipation, ageing of TCS coatings). There is no decreased equipment unit power dissipation on the payload (electrical). The PICARD payload thermal control system included several temperature control techniques: reflective covers, coatings, insulations, and heat sinks. Ageing of the covers, coatings and insulations was expected to be cumulative with time. This general ageing of the thermal control system might be observed in the long-term increase of specific temperatures. When temperatures change (orbital variation, effect of eclipses, long-term variation), instrument performance is affected.

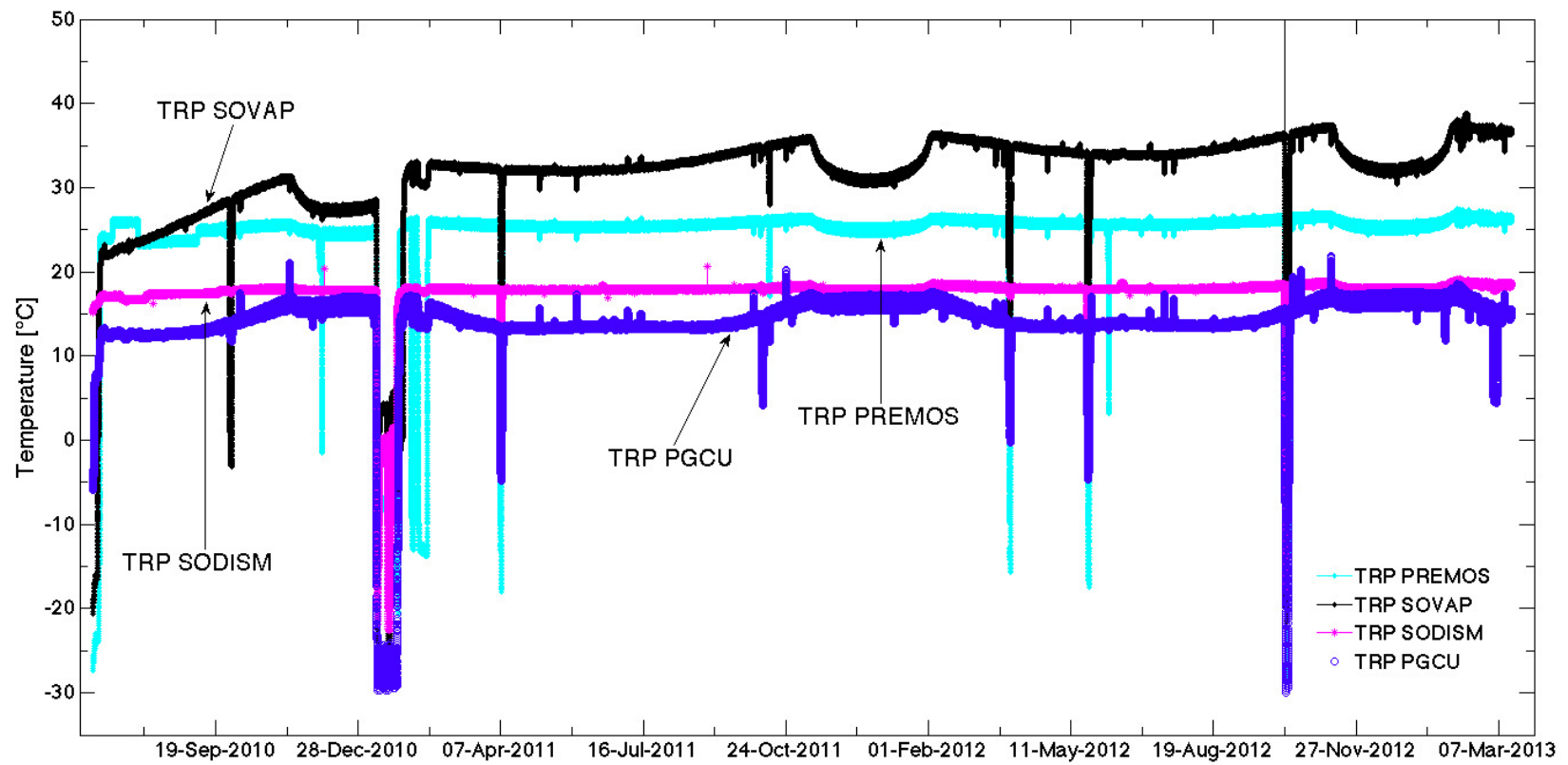

Figure 10. Temperature Reference Point (TRP) changes in orbit.

The temperature of the PREMOS instrument remains stable. The instrument is temperature controlled and a Sun-shield is used to limit the effects of solar radiation. However, we observe a decrease of the power allocated to the heating of the instrument (there is indeed a degradation related to the space environment). The Sun photometer has experienced a pronounced degradation since it has lost more than $99 \%$ of the signal for the UV channels and about $35 \%$ for the visible channel while more than $86 \%$ of the signal remains for the near IR (infrared) channel. The temperature of the SOVAP instrument has increased significantly since the beginning of the mission. This instrument is not temperature controlled. In addition, a radiator with a white paint is used on the front panel. In the future, we should avoid this type of design. Indeed, the stability of the instrument is not acquired (low thermal inertia, contamination of thermo-optical surfaces, ...). The evolution of the temperature of the instrument impacts the radiometric measurement (irradiance). These effects can be modelled and corrected (orbital variation, effect of eclipses, long-term variation). 
The elements of SODISM that are regulated, and not exposed to the Sun remain stable in temperature (TRP, primary mirror, interferences filters, CCD). The components at the front of the instrument (facing the Sun) have more significant temperature variations. The front window temperature (mechanical interface) varies significantly during the orbit (orbital variation) and its modulation with the latitude of the Earth depends on the position of the spacecraft (Figure 11). SODISM solar radius measurement has the same behaviour (Figure 12). This effect is observed during a special spacecraft operation (telescope optical distortion determination).
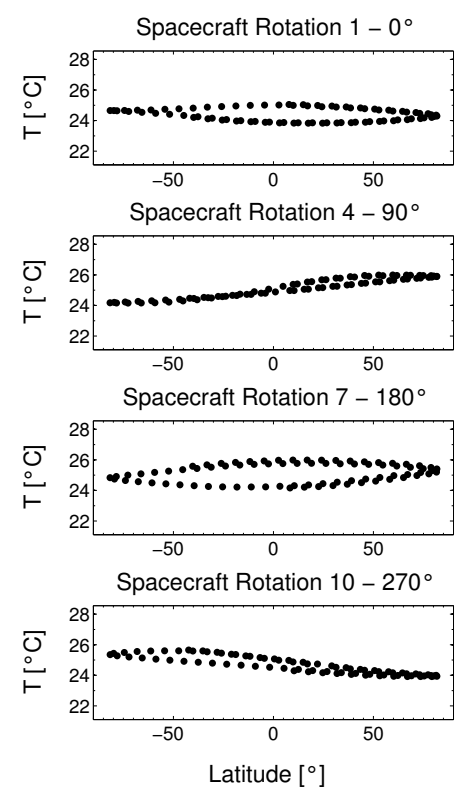
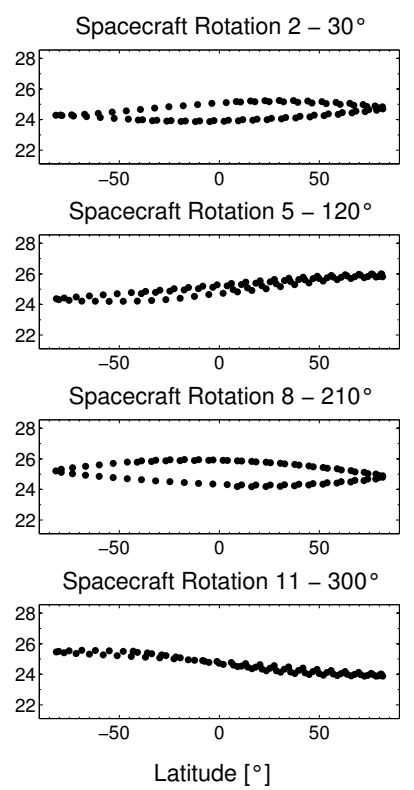
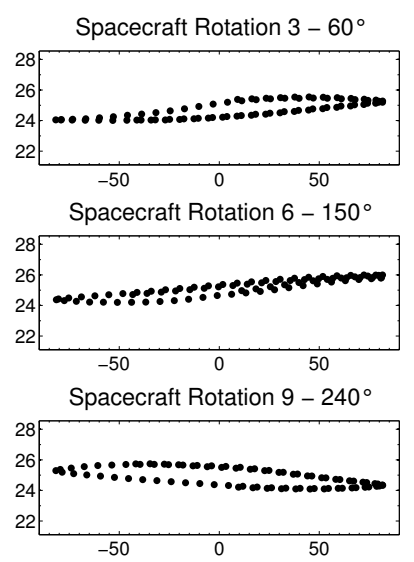

Spacecraft Rotation $12-330^{\circ}$

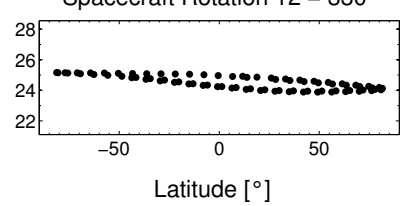

Figure 11. Temperature variation of the front window (mechanical interface) during spacecraft rotation (July 4, 2011).

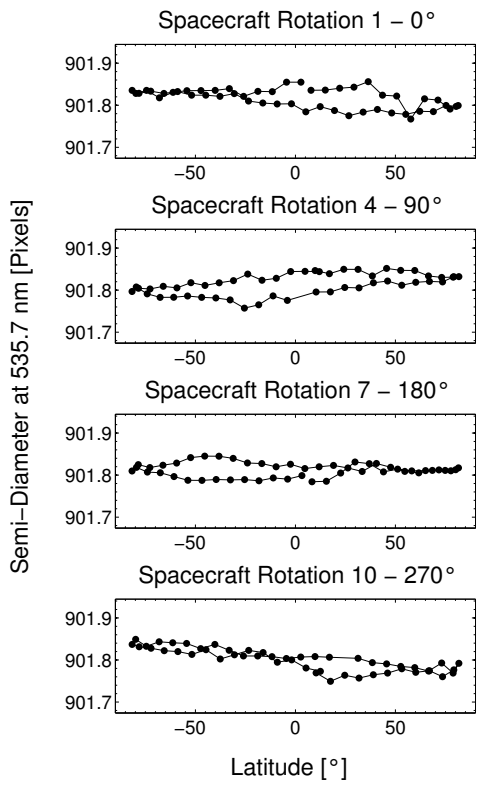

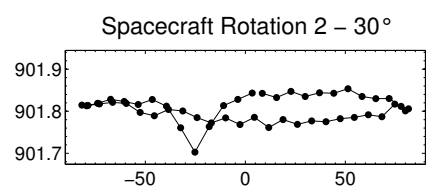
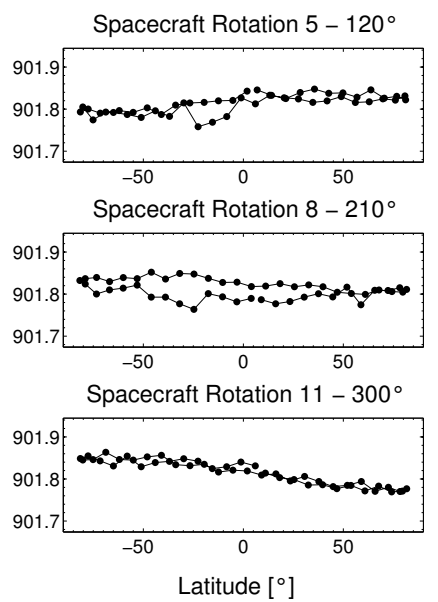
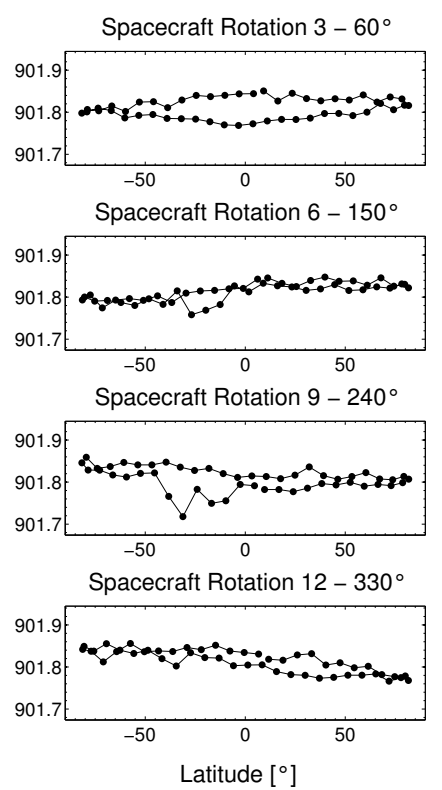

Figure 12. SODISM Solar radius measurements at $535.7 \mathrm{~nm}$ during spacecraft rotation (July 4, 2011). 
The SODISM front window temperature (mechanical interface) varies greatly since the beginning of the mission (long-term variation). During periods of eclipse, we can observe rapid changes (Figure 13). Solar instruments are particularly vulnerable because their optical elements are exposed to unshielded solar radiation. The front window is located at the pupil of the telescope. It is necessary to ensure low temperature gradient (spatial $\delta T / \delta x$ ), and low temperature variation (temporal $\delta T / \delta t$ ) for the front window. The value of the temperature gradient can be obtained by numerical modelling. For this, it is necessary to know the incident flux on the front window (solar, Earth reflected solar, planetary IR, see Figure 6). In addition, we need to know the thermo-optical properties of the front window (solar absorptance $\alpha$, emissivity $\varepsilon$, see Table 3). The front window gradient (from the centre of the glass outward) has a direct impact on the instrumental performance. The achieved model shows a significant temperature gradient on the front window $\left(\sim-7^{\circ} \mathrm{C}\right)$. The core temperature of the front window is lower than the edge (initial solar absorptance too low). This gradient varies (orbital effect), and changes over time (Earth eclipse, declination, and ageing). In the following sections, we need to understand SODISM observational results and how a temperature gradient can impact performances.

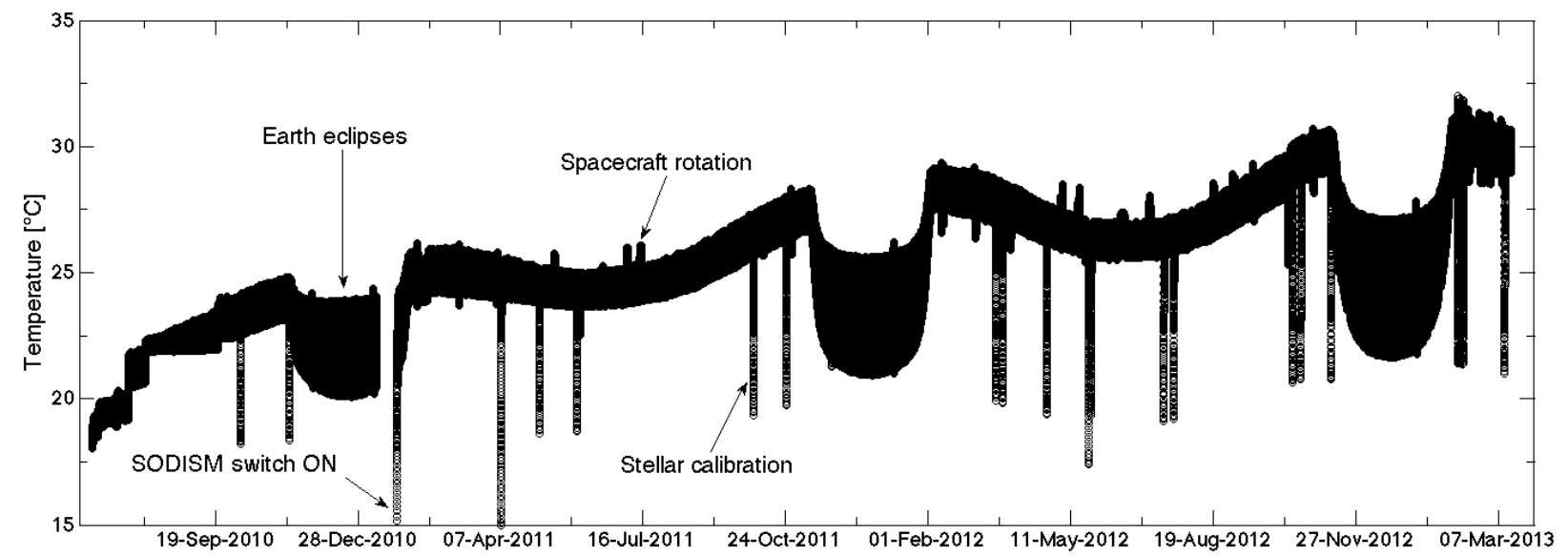

Figure 13. General ageing of the thermal control of the payload (temperature of the front window interface).

\section{SODISM IN SPACE AND OBSERVATIONAL RESULTS}

SODISM is in good instrumental health. Its door was opened in July 2010. Its two filter wheels and one-shutter mechanism operate flawlessly 24-7-365 since then, almost every minute. As to its flight software, no substantial errors were encountered; commanding and onboard data handling perform largely as they were intended to. The Level 0 (L0) data products are correctly generated every day at the PICARD Payload Data Center situated at BUSOC in Brussels. SODISM has recorded more than one million solar images since the beginning of the mission in June 2010 and is still operating in 2013. The upper part of Figure 14 shows a sample of (Level 1) solar images recorded in August 2010 with SODISM at the five wavelengths while the lower part represents solar images recorded in February 2013. They have been all corrected from dark current and flat field. We observe in Figure 14 that images recorded at $215.0 \mathrm{~nm}$, and at $393.37 \mathrm{~nm}$ (Ca II K) exhibit a flatter CLV (centre-to-limb variation) in 2013. This is due to the expected loss of sensitivity in these ultraviolet channels. It is interesting to monitor the integrated intensity in SODISM images at all wavelengths. This has been computed since the beginning of the mission and displayed in Figure 15. As visible in this Figure, UV channels have experienced a pronounced degradation since the ' 215 ' channel has lost more than $90 \%$, and ' 393 ' about $\mathbf{8 0} \%$. The degradation is probably induced by the polymerisation of contaminants on the front window and/or on the other optical elements under solar UV exposure (photochemical deposition of contaminant with solar UV and outgassing contamination). Note that the integrated intensity for the visible and near infrared channels presents a temporal oscillation but remains relatively constant. We are currently investigating why the degradation is not a decreasing function for all channels (radiation may stimulate outgassing, charging may enhance contaminant rate, atomic oxygen may clean contaminant surfaces, ...). 

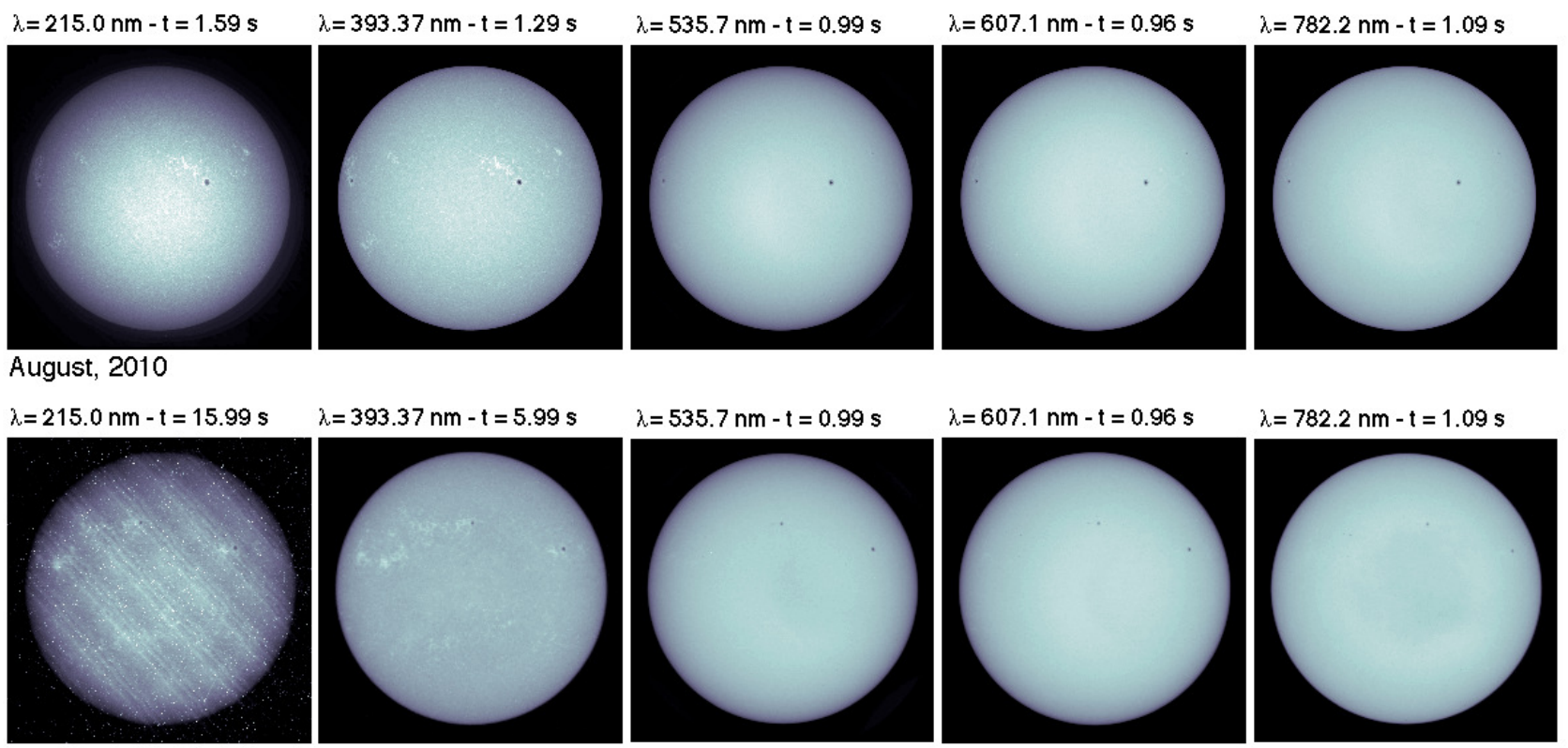

February, 2013

Figure 14. Sun surface at different wavelength and for different time (Level 1 data products).

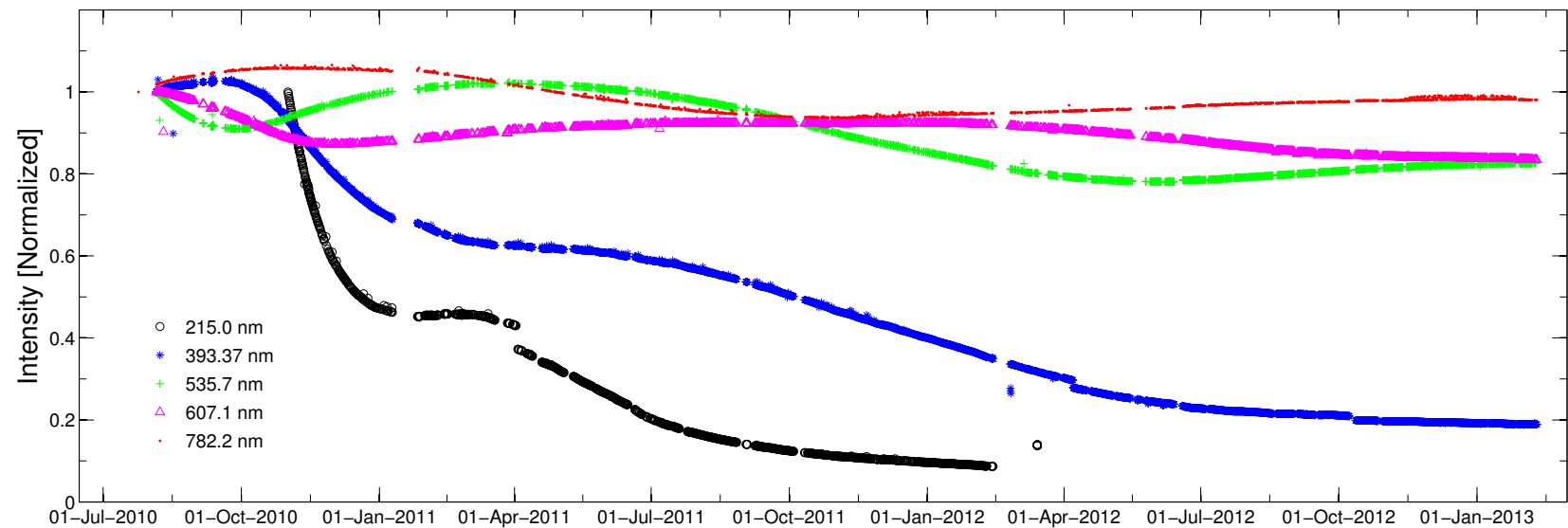

Figure 15. Normalized time series for all channels since the beginning of the mission.

We also studied the quality of the first SODISM images to see whether one of the scientific objectives might be achieved i.e. the solar diameter measurement. In this section we consider solar images recorded at $607.1 \mathrm{~nm}$. We first extract radial cuts in the image, which corresponds to the limb darkening intensity function of the Sun as seen through the instrument. We compare them with a theoretical model of the limb darkening function ${ }^{6}$ convolved with the PSF (point spread function) of the instrument. The PSF is obtained with an optical model of the instrument designed with the ZEMAX software. The left side of Figure 16 compares the convolved LDF (limb darkening function) at $607.1 \mathrm{~nm}$ with the LDF actually observed. We next compute the first derivative of those two LDFs to better evaluate their spread, which gives an indication of the image quality (right side of Figure 16). We observe that the solar limb recorded with SODISM is wider than the spread expected from the model. The slope of the observed intensity profile - defined as the Full Width at Half (or $70 \%$ ) Maximum (FWHM) of its first derivative - is wider than expected by $\sim 3$ arcsec. This is probably due to some misalignment of the optical elements combined with thermo-optical effects, which can also blur the image. In itself, this does not disqualify the scientific objective since it is equivalent to having a telescope with a smaller aperture, giving the same PSF as observed. But it would have to be time invariant, i.e. constant during the 
entire mission. However, the limb width varies with time: it displays a modulation in phase with the orbit due to Earth atmospheric radiation, which affects the observations, ${ }^{7}$ as well as a long-term trend toward worsening (Figure 17). Additionally, the solar limb at the equator is more spread out than the limb at the pole. And finally, the shape of the solar figure departs more and more from perfect circularity. The residual pattern (after subtraction of the largely dominant sphericity) reveals a triangular "trefoil" outline.
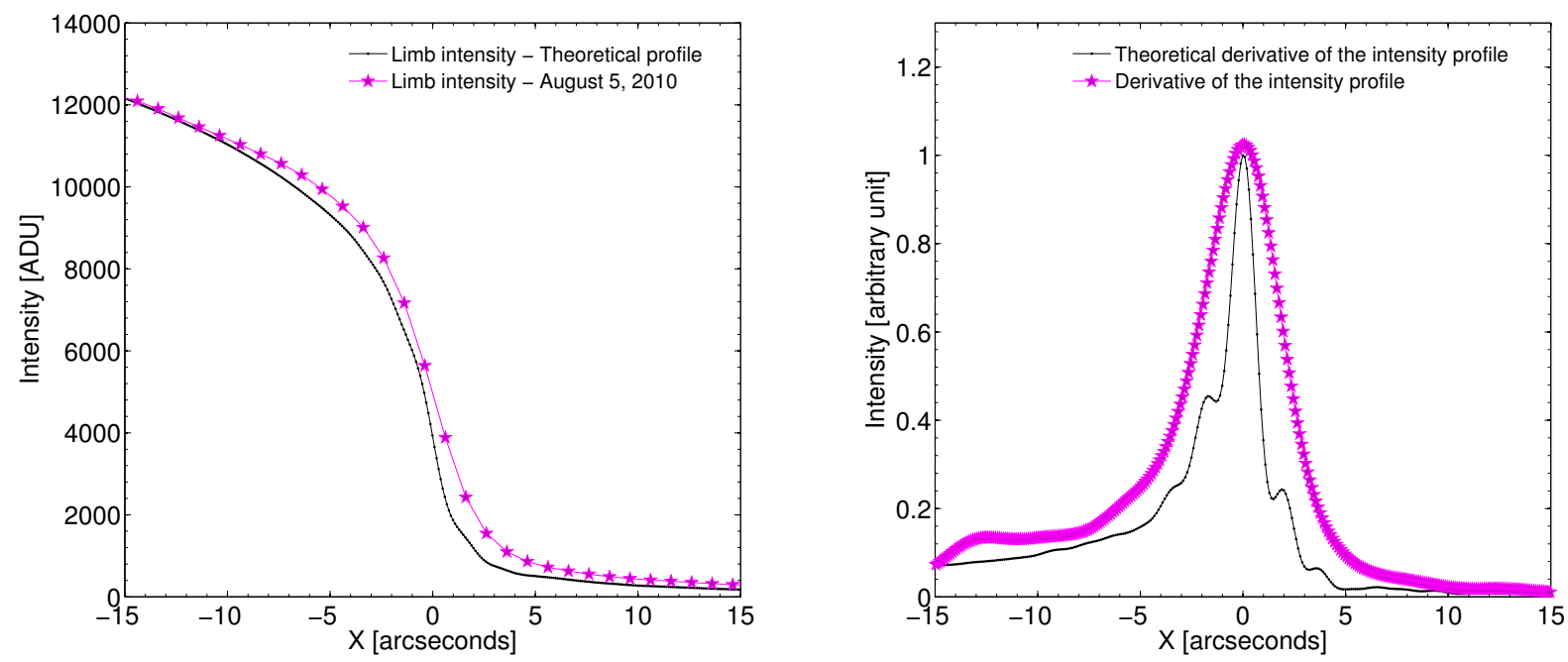

Figure 16. SODISM limb intensity at $607.1 \mathrm{~nm}$ (on left), and SODISM derivative of the intensity profile (on right).

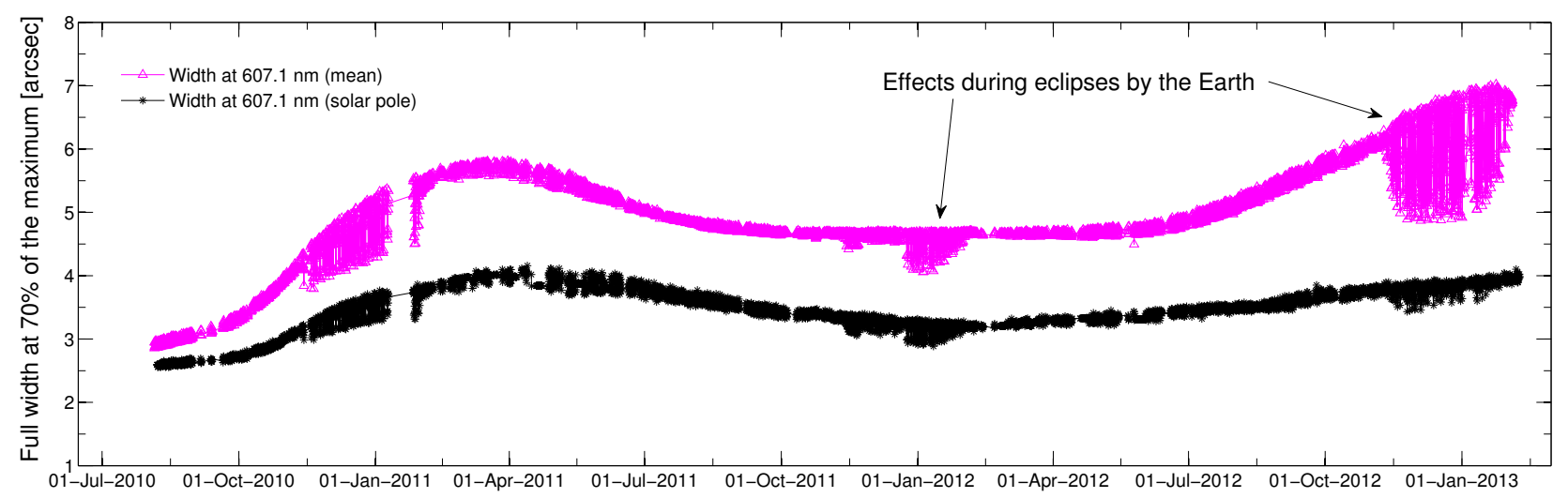

Figure 17. Variation of the limb width at $70 \%(607.1 \mathrm{~nm})$ since the beginning of the mission.

The temporal variations shown in Figure 17, do not have a random behaviour. They can be modelled, and it is actually our challenge to develop the model that will allow data corrections for the instrumental changes. The Venus transit has been observed with PICARD on June 5-6, 2012. For this occasion, special observations were planned and they already appear very useful for the purpose of PSF calibration and modelling.

\section{SPACE ENVIRONMENT AND EFFECTS}

A spacecraft requires consideration of how it will interact with the environment (Table 8). Space environment specifications contain that information, are set early in the mission design, and are passed on to the laboratories just like the launch environment. High local temperatures on sunlit surfaces and low ambient pressures encourage vaporisation of high vapour-pressure materials (solar panel). Low local temperatures on shaded or operationally cooled surfaces can induce condensation of volatiles lost from sunlit surfaces. This effect is a major source of 
on-orbit contamination. Solar UV generates colour changes and embrittlement of optical coatings and thermal coatings (photochemical deposition of contaminant). Furthermore, radiation may stimulate outgassing and charging may enhance contaminant rate. All these phenomena are complex. Investigation and analysis of the degradation variation on space instruments are crucial parts of achieving the scientific goals of all such instruments. Remote sensing instrumentation exposed to the space environment usually degrades due to the harsh environment in which the instruments are expected to operate. The PICARD payload is particularly vulnerable because its optical elements (PREMOS and SODISM) and radiators (SOVAP) are exposed to unshielded solar radiation. SODISM has suffered substantial degradation due to a combination of solar irradiation and instrumental contamination that can cause polymerisation of organic material and, subsequently, irreversible deposition of this material on the instrument optical surfaces.

Table 8. Space environment hazards on PICARD payload.

\begin{tabular}{|l|l|l|}
\hline Environment & Effects & hazards \\
\hline Logistics and launch & Shock, dirt, pressure changes, optical alignment & Relevant \\
Microgravity & Fluid management, Mechanisms & Relevant \\
Vacuum and solar UV & Outgassing, contamination & Important \\
Neutral atmosphere & Atomic oxygen attack & Relevant \\
Plasma environment (protons, electrons) & Surface charging, electrostatic discharge & Relevant \\
Radiations (solar particle events) & Total dose degradation, Single Event Effects & Relevant \\
Radiations (trapped radiation belts) & Total dose degradation, Single Event Effects & Relevant \\
Radiations (galactic cosmic rays) & Total dose degradation, Single Event Effects & Relevant \\
Orbital debris & Impact & Relevant \\
\hline
\end{tabular}

\section{DISCUSSION ON SODISM OBSERVATIONS}

The measurement of solar diameter with PICARD is very difficult and some constraints appear:

- Low mass of the spacecraft (thermal inertia and orbital variation),

- Low spacecraft altitude for LEO orbit (Earth reflected solar flux, planetary IR flux, eclipses, ...),

- Low electrical power allocated to the spacecraft thermal control (CCD needs to be kept at cold temperatures and during non-operational phases, it is necessary to maintain the CCD at a temperature above its environment to reduce the risk of contamination).

In addition, space is a harsh environment for optics with many physical interactions leading to potentially severe degradation of optical performance. The type of degradation that can affect SODISM is the degradation of image quality due to combination of solar irradiation and instrumental contamination. First, we will try to determine the temperature gradient $\delta T$ in the front window. In fact, this contamination is manifested by an increase in temperature at one-year interval (Table 9 ).

Table 9. Total absorbed flux on the front window and temperature gradient for different cases in orbit (model).

\begin{tabular}{|l|l|l|l|l|l|}
\hline Date & $01 / 09 / 10$ & $01 / 11 / 10$ & $01 / 03 / 11$ & $01 / 03 / 12$ & $01 / 03 / 13$ \\
\hline Solar flux & 201.0 & 207.8 & 208.6 & 208.5 & 208.4 \\
Earth reflected solar flux (albedo) & 2.6 & 2.5 & 2.6 & 2.6 & 2.6 \\
Planetary IR flux & 43.4 & 45.2 & 44.3 & 44.3 & 44.3 \\
Total flux (absorbed) in W/m ${ }^{2}$ & 247.0 & 255.6 & 255.5 & 255.4 & 255.4 \\
Temperature of the core T1 & 18.5 & 20.4 & 21.6 & 24.1 & 25.3 \\
Temperature of the edge T2 & 27.0 & 29.0 & 30.8 & 34.6 & 36.5 \\
Temperature gradient $\delta T$ in ${ }^{\circ} \mathbf{C}$ & $\mathbf{- 8 . 5}$ & $\mathbf{- 8 . 6}$ & $\mathbf{- 9 . 2}$ & $\mathbf{- 1 0 . 5}$ & $\mathbf{- 1 1 . 2}$ \\
\hline
\end{tabular}

The temperature gradient $\delta T$ changes over time from $\sim-7^{\circ} \mathrm{C}$ to $\sim-12^{\circ} \mathrm{C}$. From SODISM optical model, we apply a thermal gradient at the front window (quadratic form with phase defect - focus). The new 

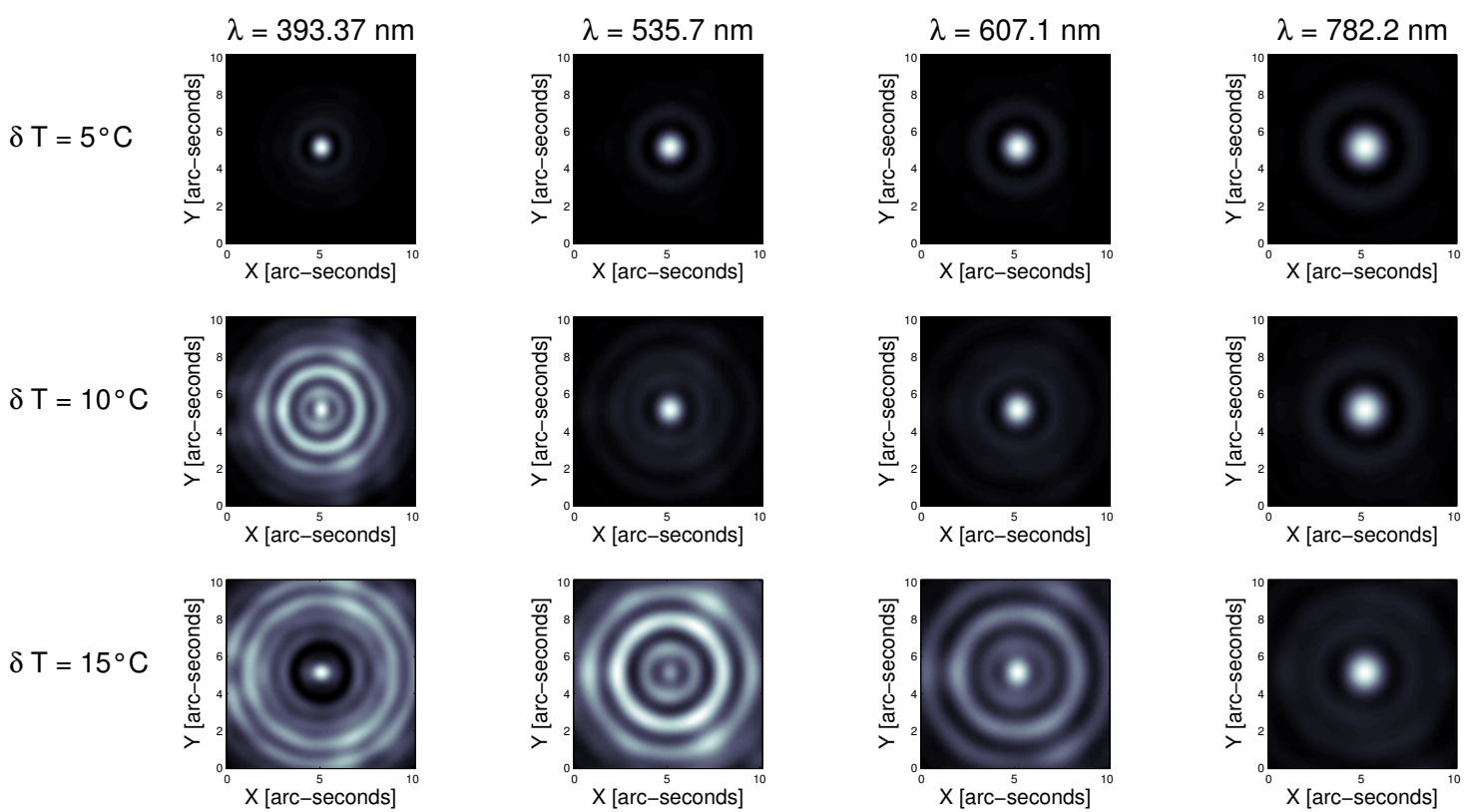

Figure 18. SODISM PSF for each wavelength - quadratic gradient on the front window from $-5^{\circ} \mathrm{C}$ to $-15^{\circ} \mathrm{C}$.
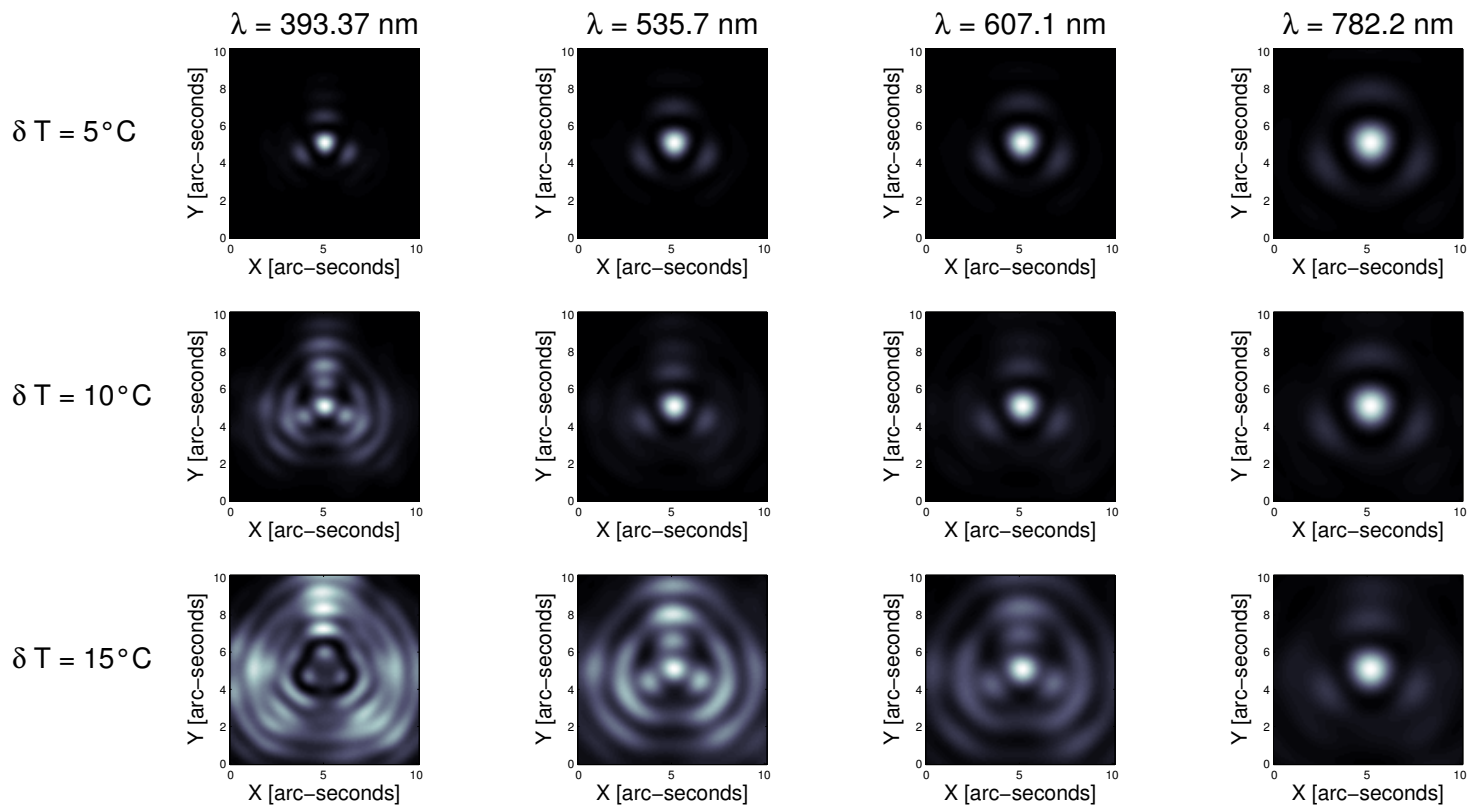

Figure 19. SODISM PSF - quadratic gradient on the front window from $-5^{\circ} \mathrm{C}$ to $-15^{\circ} \mathrm{C}$ and a static defect on the primary mirror with a relatively low amplitude (of the order of few tens of nm RMS), consisting of three bumps ("trefoil").

SODISM PSF (case 1) is obtained with an optical model of the instrument designed with the Code V software (Figure 18). If we use a theoretical model of the limb darkening function ${ }^{6}$ convolved with the PSF of the instrument, we get the solar limb derivative for different cases of temperature (Figure 20). This analysis case causes a significant defocus of the instrument. However, it does not highlight the triangular shape ("trefoil") that we see in our SODISM images. We can consider that the defect that we observe has a multi-causal origin 
(initial optical alignment, thermal gradient at the front window, and "trefoil" defect on the primary mirror with a relatively low amplitude). A new SODISM PSF (case 2) is obtained with an optical model of the instrument (Figure 19). This study case is very interesting. It highlights how a small defect associated with a defocus can be amplified. Due to the nature of solar profiles, the results (deviation from the mean circle) have a spectral dependence (Figure 21). Analysis case 2 (thermal gradient on the front window and "trefoil" on the primary mirror) seems credible. Indeed, we have demonstrated that a thermal gradient existed at the front window and it evolved over time. In addition, the defect highlighted at the primary mirror is realistic (polishing defect, and or thermal gradient in the primary mirror where the thermal shunts are located). This analysis highlights the fact that from $-8^{\circ} \mathrm{C}$ of mean thermal gradient on the front window, the PSF of the instrument deteriorates considerably. Around this operating point, and with a change in temperature gradient of $-4^{\circ} \mathrm{C}$, the consequences are dramatic for instrumental performance. The temperature gradient varies over an orbit (IR flux distribution of the Earth). With one-year interval, the IR flux of the Earth varies very little (Figure 22). Therefore, the temperature gradient should remain constant at one year intervals. And yet, this is not the case. Environmental effects have changed the PSF of the instrument over time.

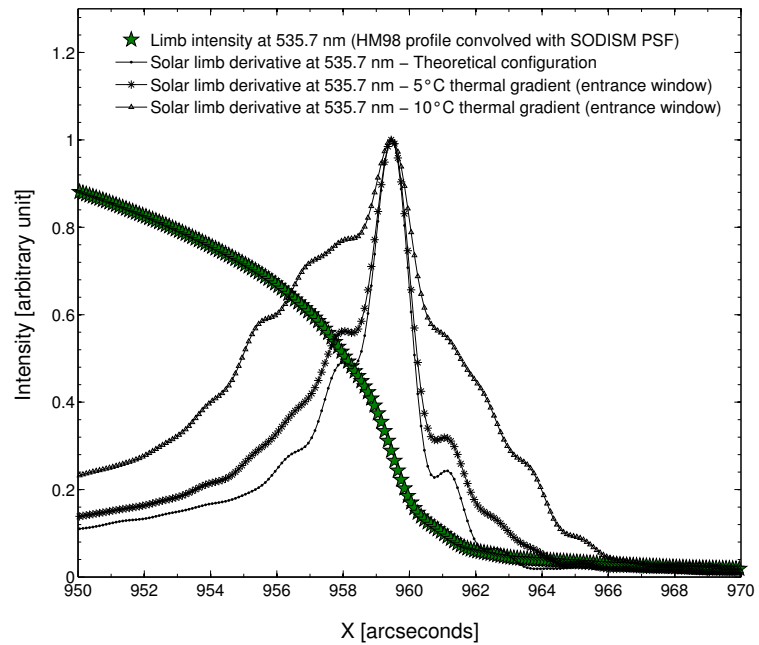

Figure 20. Solar limb derivative evolution at $535.7 \mathrm{~nm}$ (simulation) - effect of the gradient $\delta T$ on the window.

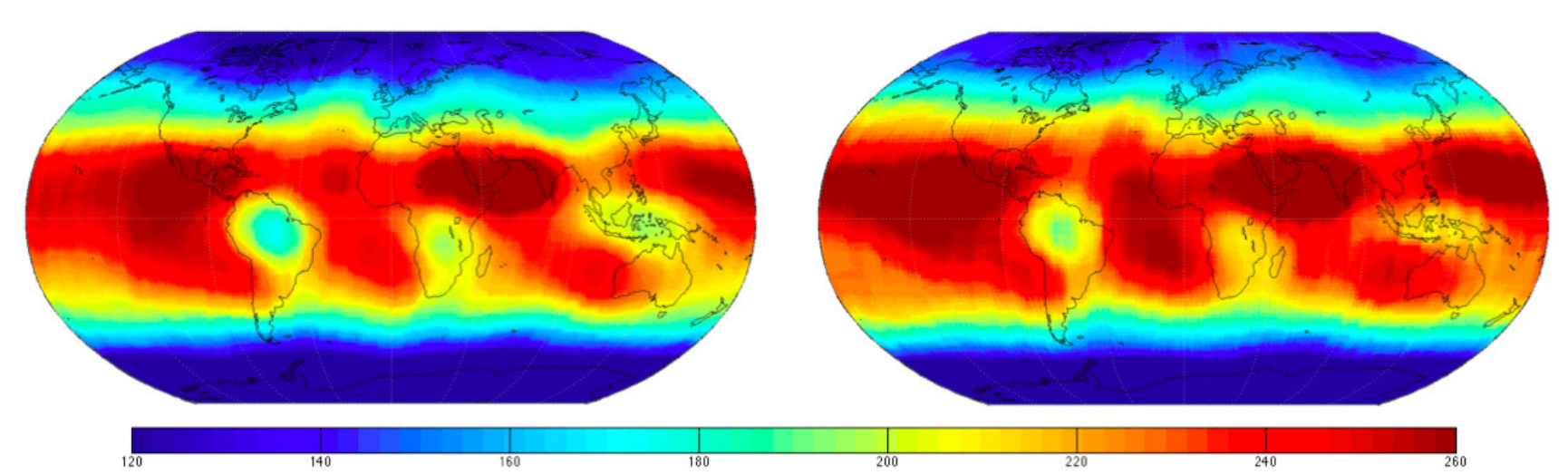

Figure 22. OLR obtained with PICARD data - March 2011 (left) and March 2012 (right).

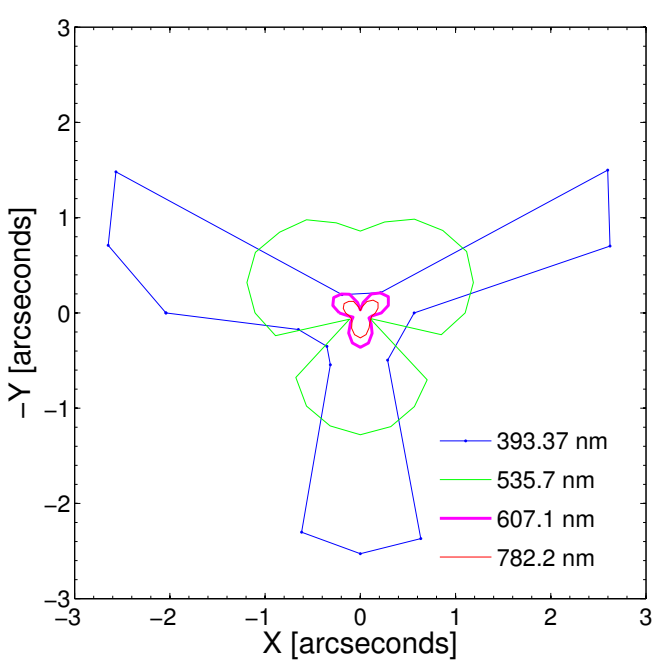

Figure 21. SODISM shape image for all wavelength (with a gradient of $11^{\circ} \mathrm{C}$ and a defect on the primary mirror). 
At the beginning of the development phase of a new project, the degradation processes will be analysed and appropriate procedures and design concepts will be developed to eliminate them. During the design phase of new solar mission, a meticulous cleanliness program will be implemented to control molecular and particle contamination. The front window of a similar instrument must be integrated into a temperature controlled enclosure. The enclosure may be regulated in temperature with a significant temperature range in order to focus the instrument. For the future solar missions associated with measures of fine metrology, it is necessary to have a lot of sensors in order to counter the effects of the space environment and try to correct the data.

A new challenge awaits us and it relates to the correction of the SODISM data with the following method:

- Determination and evolution of the solar absorptance of the SODISM front window during the mission (information supplied by the intensity measurements made by the SODISM instrument),

- Determination of the incident flux (solar, Earth IR, Earth reflected solar) on the front window (PICARD sensor, PREMOS, SOVAP),

- Estimation of the thermal gradient on the front window (PICARD/SODISM temperature housekeeping),

- Estimation of SODISM PSF (with thermal gradient) and adjustment (SODISM PSF obtained during transit of Venus, Moon eclipses, ...),

- And data corrections.

\section{CONCLUSION}

Thermal control, especially, for a payload suite is crucial to mission success. The payload thermal design validation is successful, early cruise flight data are within flight predictions. The thermal balance test correlation has successfully verified the PICARD payload thermal mathematical model, and the thermal conductance between the payload and the platform. This test was limited: it might have been better to make a thermal balance test with a solar simulator and with optical performance. The objective of this test would have been to simulate the expected solar flux on the front face of the payload during the mission (solar trapping, effect on the coatings, and solar absorptivity). Thermal coatings chosen for the PICARD payload are adequate for maintaining temperatures in the acceptable range. In flight, UV radiation degrades solar absorptivity exponentially with time. Outgassing, and contamination affect thermo-optical properties. The PICARD payload is particularly vulnerable because its optical elements and radiators are exposed to unshielded solar radiation. The low mass of the PICARD spacecraft, low spacecraft altitude, and low electrical power allocated to the payload thermal control are constraints that limit the quality of measurements. Performance of the instrument is affected by the variability of fluxes seen in orbit (direct solar radiation, planetary infrared for the Earth, and Earth reflected solar). SODISM has suffered substantial degradation due to a combination of solar irradiation and instrumental contamination that can cause polymerisation of organic material and, subsequently, irreversible deposition of this material on the instrument optical surfaces (in particular on the front window). The SODISM measurements show a complex dependency of the optical behaviour with thermal (short-term, seasonal, and ageing), and contamination effects (intermediate, and long-terms). The SODISM front window is located at the pupil of the telescope. The temperature gradient $\delta T$ (from the centre of the glass outward) changes over time from $\sim-7^{\circ} \mathrm{C}$ to $\sim-12^{\circ} \mathrm{C}$ (space environment and effects) and has a direct impact on the instrumental performance (if the gradient increases, images become blurred and the PSF deteriorates). This effect is very difficult to characterise through a ground test (temperature uncertainty for a simply thermal balance is $\sim 5^{\circ} \mathrm{C}$ ). It is necessary to identify the lessons learned from the PICARD project. The use of radiators facing the Sun is not a good compromise. We must advocate the use of Sun shield to guard against the important effects of ageing on thermal coatings. The front window of a similar instrument must be integrated into a temperature controlled enclosure and a meticulous cleanliness program will be implemented. 


\section{ACKNOWLEDGMENTS}

PICARD is a mission supported by the Centre National d'Etudes Spatiales (CNES), the CNRS/INSU, the Belgian Space Policy (BELSPO), the Swiss Space Office (SSO), and the European Space Agency (ESA). We thank CNES, and CNRS (Centre National de la Recherche Scientifique) for their support as well as all participants who have devoted their expertise to this study (P. Etcheto, J. Gayrard, R. Briet, F. Riguet, ...).

\section{REFERENCES}

1. Thuillier, G., Dewitte, S., and Schmutz, W., "Simultaneous measurement of the total solar irradiance and solar diameter by the picard mission," Advances in Space Research 38(8), 1792 - 1806 (2006).

2. Schmutz, W., Fehlmann, A., Hülsen, G., Meindl, P., Winkler, R., Thuillier, G., Blattner, P., Buisson, F., Egorova, T., Finsterle, W., Fox, N., Gröbner, J., Hochedez, J.-F., Koller, S., Meftah, M., Meisonnier, M., Nyeki, S., Pfiffner, D., Roth, H., Rozanov, E., Spescha, M., Wehrli, C., Werner, L., and Wyss, J. U., "The PREMOS/PICARD instrument calibration," Metrologia 46, 202 (Aug. 2009).

3. Conscience, C., Meftah, M., Chevalier, A., Dewitte, S., and Crommelynck, D., "The space instrument SOVAP of the PICARD mission," in [Society of Photo-Optical Instrumentation Engineers (SPIE) Conference Series], Society of Photo-Optical Instrumentation Engineers (SPIE) Conference Series 8146 (Sept. 2011).

4. Meftah, M. and Irbah, A., "The space instrument SODISM, a telescope to measure the solar diameter," in [Society of Photo-Optical Instrumentation Engineers (SPIE) Conference Series], Society of Photo-Optical Instrumentation Engineers (SPIE) Conference Series 8146 (Sept. 2011).

5. Barkstrom, B., Harrison, E., Smith, G., Kibler, J., and Green, R., "Earth Radiation Budget Experiment (ERBE) archival and April 1985 results," Bulletin of the American Meteorological Society 70, 1254-1262 (Oct. 1989).

6. Hestroffer, D. and Magnan, C., "Wavelength dependency of the Solar limb darkening," Astron. Astrophys. 333, 338-342 (May 1998).

7. Irbah, A., Meftah, M., Hauchecorne, A., Cisse, E. h. M., Lin, M., and Rouzé, M., "How Earth atmospheric radiations may affect astronomical observations from low-orbit satellites," in [Society of Photo-Optical Instrumentation Engineers (SPIE) Conference Series], Society of Photo-Optical Instrumentation Engineers (SPIE) Conference Series 8442 (Sept. 2012). 